\title{
EVALUATION OF THE ACCURACY OF THE IMPLEMENTATION OF DYNAMIC EFFECTS IN THE QUASI STEADY-STATE CALCULATION METHOD FOR SCHOOL BUILDINGS
}

\author{
B. Wauman ${ }^{1,2}$; H. Breesch ${ }^{2}$; D. Saelens ${ }^{1}$;
}

1: Building Physics Section, Department of Civil Engineering, KU Leuven, Kasteelpark Arenberg 40 - box 2447, 3001 Heverlee, Belgium.

2: Catholic University College, Sustainable building, Gebroeders De Smetstraat 1, B-9000 Ghent, Belgium

Corresponding author: Barbara Wauman, Building Physics Section, Department of Civil Engineering, KU Leuven, Kasteelpark Arenberg 40, box 2447, BE-3001 Leuven (Heverlee), Belgium, Tel. +32 16 321347, Fax. +32 16 321980, barbara.wauman@bwk.kuleuven.be

\section{AbSTRACT}

The quasi steady-state calculation method (based on EN ISO 13790) is commonly used for energy performance checking. This method attempts to accurately represent the building's energy use. However, intermodal comparison of dynamic and static calculations reveal quite some discrepancies often caused by the inaccuracy of the gain utilization factor and the temperature setback approach used for intermittently heated buildings. This paper tries to improve the method for schools buildings focusing on the gain utilization factor $\eta_{\mathrm{H}, \mathrm{gn}}$ and the parameters $\mathrm{a}_{0}$ and $\tau_{0}$ in particular. These parameters will be adapted to the Flemish climate and the typical characteristics of school buildings. The Monte Carlo analysis technique is applied to cover the broad spectrum of influential parameters. Based on the comparison of dynamic and static calculation results, a regression analysis is performed to determine the correlation between the heat-balance ratio $\gamma_{\mathrm{H}}$ and the gain utilization factor $\eta_{\mathrm{H} \text {,gn. }}$ Although more accurate results are found using the adapted dynamic parameters $\mathrm{a}_{0}=1.4$ and $\tau_{0}=185$, the quasi steady-state method for school buildings remains unreliable as the accuracy of the method is simultaneously determined by the value of the gain utilization factor and by the assessment of the adjusted set-point temperature. 


\section{KEY WORDS}

Quasi steady-state calculation method; gain utilization factor; school buildings; intermittency 


\section{Evaluation of the accuracy of the implementation of dynamic}

\section{effects in the quasi steady-state calculation method for school}

\section{buildings}

B. Wauman ${ }^{1,2}$; H. Breesch ${ }^{2}$; D. Saelens ${ }^{1}$;

1: Building Physics Section, Department of Civil Engineering, KU Leuven, Kasteelpark Arenberg 40 - box 2447, 3001 Heverlee, Belgium.

2: Catholic University College, Sustainable building, Gebroeders De Smetstraat 1, B-9000 Ghent, Belgium

Corresponding author: Barbara Wauman, Building Physics Section, Department of Civil Engineering, KU Leuven, Kasteelpark Arenberg 40, box 2447, BE-3001 Leuven (Heverlee), Belgium, Tel. +32 16 321347, Fax.+32 16 321980, barbara.wauman@bwk.kuleuven.be

\section{INTRODUCTION}

As the building sector is responsible for nearly $38 \%$ of EU final energy consumption [1], the building energy performance became a prior concern for the European Union in the attempt to meet the Kyoto commitment. As a result, the European Directive 2002/91/EC on the Energy Performance of Buildings was formed [2] and since its implementation the number of very low energy buildings and passive non-residential buildings has increased significantly $[3,4]$. In Flanders (Belgium), the evolution towards more energy efficient schools in particular was boosted in 2009 by the approval and subsidizing of 24 passive schools, covering almost $65000 \mathrm{~m}^{2}$. The following criteria for Flemish passive schools were set forward by the government:

$1^{\circ}$ annual net energy need for heating $\leq 15 \mathrm{kWh} /\left(\mathrm{m}^{2} . \mathrm{a}\right)$

$2^{\circ}$ annual net energy need for cooling $\leq 15 \mathrm{kWh} /\left(\mathrm{m}^{2} . \mathrm{a}\right)$ 
$3^{\circ}$ maximum air tightness level $\left(\mathrm{n}_{50}\right) \leq 0,6 \mathrm{~h}^{-1}$

$4^{\circ}$ maximum E-level $=55$ (primary energy performance level as required by EPB [5])

Two main methods exists for performance compliance checking: quasi steady-state methods, which calculates the heat balance in steady-state conditions over a sufficiently long time (i.e. one month) and dynamic methods, which calculates the heat balance with shorter time steps (typically one hour) [6]. The choice between both methods typically depends on the use of the building (residential, office, etc.), the complexity of the building and/or systems, the time available by the research team and the application (energy performance requirement, energy performance certificate or recommended energy performance measures,...). As building regulations particularly stipulate that the prescribed method is transparent, robust and reproducible [7], the quasi steady-state monthly single-zone calculation method is often used for performance compliance checking giving a simple and traceable indication of the energy performance of buildings [8]. On the other hand, due to the simplicity of the method, dynamic effects (e.g. climatic conditions, user behaviour, time schedules, ...) are only taken into consideration in a simplified way by time weighted averaged values and dynamic factors while the dynamic methods consider accumulation, dynamic phenomena and variations of numerical values in a more realistic way. In conformity with EN ISO 13790, the quasi steadystate method uses following factors to cover the dynamic effects:

- an adjustment of the set-point temperature to factor in the intermittent heating pattern or switch offs, depending on the variations of the set-point temperature and the length of the set-back period 
- the empirically determined gain utilization factor $\eta_{\mathrm{H}, \mathrm{gn}}$ for the combined internal and solar heat gains

The quasi steady-state method is determined to his current form in the PASSYS project $[9,10]$ aiming at the development of an easy evaluation tool for monthly energy need for heating of dwellings. The accuracy of this method, with respect to the determination of the energy needs for heating, has been investigated in various research activities [7,11]. Loga et al. compared the results of static calculations in conformity with EN 832 to the results of dynamic simulations in DYNBIL and found satisfactory results for continuously heated buildings [11]. Van Dijk et al. [7] compared the monthly calculation results with results available from detailed simulation methods and simple hourly calculations. Based on the satisfying results of validation tests, they found the monthly method to be well suited for energy compliance checking for residential buildings. However, according to the same researches further finetuning of the method, in particular for intermittent heating, is still necessary as fairly high discrepancies for discontinuously heated buildings remained [7,11]. Likewise, Kokogiannakis [12] compared the monthly method of EN ISO 13790 to the results of the detailed modelling programs EnergyPlus and ESP-r. He observed a general trend for the monthly method to overestimate the need for heating for intermittently used office buildings. All three previous studies mentioned the gain utilization factor in the quasi steady-state method as a potential reason for the differing outcomes of the intermodal comparison concluding that this factor is a decisive factor in the accuracy of the calculation method.

Additionally, several researches [13-15] investigated the accuracy of the gain utilization factor in relation to the use and the typology of the building. Jokisalo and Kurnitski [13] investigated the applicability of the quasi steady-state calculation for modern buildings in the 
Nordic climate. From the comparison of dynamic simulations (IDA-ICE) with the results of the monthly energy balance method they concluded the need to adapt the numerical parameters to enhance the accuracy of the quasi steady-state model for residential buildings. Moreover, their study indicated that the monthly method of EN ISO 13790, even with newly determined numerical parameters, should not be applied for office buildings. Likewise, Corrado and Fabrizio $[14,15]$ studied the accuracy of the utilization factor in relation to the Italian climate, typology, construction and user. All studies [13-15] demonstrated it would be more appropriate to specifically adapt the monthly calculation method, and in particular the gain utilization factor, to the use and typology of the building. Based on these conclusions, this paper tries to improve the accuracy of the monthly calculation model in particular for schools buildings.

Many characteristics of schools (features, occupancy, gains, control) differ significantly compared to residential buildings or offices. In contrast, schools typically have a strongly discontinuous user profile and very high occupant densities. As all these characteristics considerably affect the energy need for heating, their impact should be acknowledged in the monthly calculation method. In particular, the gain utilization factor $\eta_{\mathrm{H}, \mathrm{gn}}$ must be adapted to the Flemish climate and the typical characteristics and user's data of school buildings.

This paper starts with an analysis of the quasi steady-state calculation method as prescribed in EN ISO 13790 and the method to implement the effect of intermittency. The gain utilization factor $\eta_{\mathrm{H}, \mathrm{gn}}$ is studied both as a value and as a trend. Secondly, the influence of the typical characteristics of schools on the accuracy of the quasi steady-state calculations is evaluated. Therefore, the dynamically calculated energy need for heating is compared to the results of the quasi steady-state calculation method, both performed using the same BES program, 
TRNSYS [16]. As the value of the gain utilization factor $\eta_{\mathrm{H}, \mathrm{gn}}$ depends on many parameters (building's characteristics, users' behaviour, time and spatial distribution of the free gains,...) a large number of calculations is done using the Monte Carlo analysis technique (MCA). Finally a regression analysis is performed to determine the correlation between the heatbalance ratio $\gamma_{\mathrm{H}}$ and the gain utilization factor $\eta_{\mathrm{H}, \mathrm{gn}}$ and adapted values for the gain utilization factor $\eta_{\mathrm{H}, \mathrm{gn}}$ are set.

One has to keep in mind that, since this analysis has been restricted to a an elementary school, the outcome must be considered as an indication. Further research on other school typologies (secondary education, general $\rightarrow$ vocational) is necessary to see whether similar results are found.

\section{QUASI STEADY-STATE CALCULATION METHOD}

The quasi steady-state calculation method as prescribed in EN ISO 13790 is studied. The calculation of the heat balance and the method to implement intermittent phenomena are analysed.

\subsection{Calculation of heat Balance}

The quasi steady-state calculation method of the heat balance was determined in the PASSYS project $[9,10]$ for calculating the monthly heating requirements of buildings heated at constant set-point temperatures. The building energy need for heating based on $[9,10]$ and as defined in EN ISO 13790, is calculated as

$$
Q_{H, n d, s t a t}=Q_{H, h t}-\eta_{H, g n} Q_{H, g n}
$$


where $\mathrm{Q}_{\mathrm{H}, \mathrm{nd}, \text { stat }}$ is the statically calculated building energy need for heating $\left(\mathrm{kWh} / \mathrm{m}^{2}\right), \mathrm{Q}_{\mathrm{H}, \mathrm{ht}}$ is the statically calculated total heat transfer for the heating mode $\left(\mathrm{kWh} / \mathrm{m}^{2}\right), \mathrm{Q}_{\mathrm{H}, \mathrm{gn}}$ is the statically calculated total heat gain for the heating mode $\left(\mathrm{kWh} / \mathrm{m}^{2}\right)$ and $\eta_{\mathrm{H}, \mathrm{gn}}$, is the dimensionless gain utilization factor

if $\gamma_{\mathrm{H}} \neq 1: \eta_{H, g n}=\frac{1-\gamma_{H}{ }^{a_{0}+\frac{\tau}{\tau_{0}}}}{1-\gamma_{H}{ }^{a_{0}+\frac{\tau}{\tau_{0}}+1}}$

if $\gamma_{\mathrm{H}}=1: \eta_{H, g n}=\frac{a_{0}+\frac{\tau}{\tau_{0}}}{a_{0}+\frac{\tau}{\tau_{0}}+1}$

if $\gamma_{\mathrm{H}}<0: \eta_{H, g n}=1 / \gamma_{H}$

with $\gamma_{H}=Q_{H, g n} / Q_{H, h t}$

where $\gamma_{\mathrm{H}}$ is the dimensionless heat-balance ratio for the heating mode, $\mathrm{a}_{0}$ is a dimensionless reference numerical parameter, $\tau_{0}$ is a reference time constant, $\tau$ is the time constant of the building defined as

$\tau=\frac{C_{m}}{H_{t r}+H_{v e}}$ 
where $C_{m}$ is the accessible internal heat capacity of the building or building zone $(\mathrm{J} / \mathrm{K}), \mathrm{H}_{\mathrm{tr}}$ is a value of the overall heat transfer coefficient by transmission $(\mathrm{W} / \mathrm{K})$ and $\mathrm{H}_{\mathrm{ve}}$ is a value of the overall heat transfer coefficient by ventilation $(\mathrm{W} / \mathrm{K})$

In this approach, the gain utilization factor for the combined internal and solar heat gains $\eta_{\mathrm{H}, \mathrm{gn}}$ is introduced to take into account that only part of the internal and solar heat gains is effectively used to decrease the energy need for heating. The un-useful heat gains lead to an undesirable increase of the internal temperature above the set-point. In the approach described in EN ISO 13790, these un-useful heat gains are omitted from the heat balance equation. At the same time, extra transmission and ventilation heat transfer resulting from the increase of the internal temperature above the set-point are omitted from the heat balance equation too. The heat transfer is calculated using the internal set-point temperature for heating, thus ignoring the overheating [6].

The value for the gain utilization factor $\eta_{\mathrm{H}, \mathrm{gn}}$ depends on various parameters: the building's characteristics (type of use, thermal mass), the installed heating installation (e.g. convective or radiator heating) and the user's behaviour (set-back thermostat, use of solar shading, usage of extra ventilation in case of overheating) [17]. Since not all these influencing parameters could be taken into account the quasi steady-state calculation focuses on two parameters in particular which were assessed to be the most pertinent $[9,10]$ : the heat-balance ratio $\gamma_{\mathrm{H}}$ and the time constant of the building $\tau$. Values for $\mathrm{a}_{0}$ and $\tau_{0}$ were empirically set to be 1 and 16 for 
continuously heated dwellings [9]. A minor difference is found compared to EN ISO 13790 where the reference time constant value $\tau_{0}$ is set to 15 instead of $16[6,12]$.

Figure 1 shows the gain utilization factor for two values of the time constant of the building: $\tau$ $=150$ and $\tau=60$ which are the averaged values of the time constant for a building with a high and low thermal capacity (see $§ 3.2 .1$ ) respectively.

\section{Insert Figure 1}

In case of very low heat-balance ratios (part I in Figure 1), all heat gains can effectively be used to compensate the heat losses and thus the gain utilization factor equals one. If the energy need for heating is zero $\left(\gamma_{\mathrm{H}}\right.$ very large, part III) then the gain utilization factor equals the reciprocal number of the heat-balance ratio $\gamma_{\mathrm{H}}$. In the intermediate zone (part II), in the case where $\tau=\infty$, all gains are fully utilized until the heat gains exceed the heat losses $\left(\gamma_{\mathrm{H}}\right.$ >1). In reality however, the utilization factor decreases gradually if the time constant of the building $\tau$ decreases [17].

\subsection{IMPLEMENTATION OF DISCONTINUOUS USER PROFILES}

Schools typically have a strongly intermittent use. In Flanders, lessons are spread over five days from Monday to Friday with Wednesday afternoons free. A school day generally starts at 8.30 am and ends at $4.00 \mathrm{pm}$, except for Wednesday afternoon. Aside from weekends, a school year typically has a total of 99 days off (Table 1), assuming school closure during July and August.

\section{Insert Table 1}


In the quasi steady-state calculation method two different correction modes for heating must be considered:

- night-time and weekend reduced set-point

- reduced set-point during unoccupied periods (e.g. holidays)

\section{a) CORRECTION FOR INTERMITTENCY}

The impact of intermittence on heating operations was studied in the PASSYS II project [10] for residential buildings (single family detached and attached houses, apartment buildings) which highlighted how the heating operation affects both the heat losses and the utilized gains.

Firstly, the intermittent user profile leads to a lower mean daily indoor temperature resulting in a decrease in total heat transfer for the heating mode $\mathrm{Q}_{\mathrm{H}, \mathrm{ht}}$. Therefore EN ISO 13790 considers intermittent heating as continuous heating with an adjusted (lowered) set-point temperature $\theta_{\text {int,adj,set }}$ :

$$
Q_{H, h t}=\left(H_{t r}\left(\theta_{\text {int }, \text { adj }, \text { set }}-\theta_{e}\right)+H_{v e}\left(\theta_{\text {int }, \text { set }, o c c}-\theta_{e}\right)\right) t
$$

where $\theta_{\text {int,adj,set }}=\theta_{\text {int,set,occ }} * f_{H, o c c}+\theta_{\text {int,set,nocc }} * f_{H, \text { nocc }}$

where $\mathrm{Q}_{\mathrm{H}, \mathrm{ht}}$ is the statically calculated total heat transfer for the heating mode $\left(\mathrm{kWh} / \mathrm{m}^{2}\right), \mathrm{H}_{\mathrm{tr}}$ and $\mathrm{H}_{\mathrm{ve}}$ are the heat transfer coefficient by transmission and ventilation $(\mathrm{W} / \mathrm{K}), \theta_{\text {int,adj,set }}$ is the adjusted set-point temperature of the building for intermittent heating $\left({ }^{\circ} \mathrm{C}\right), \theta_{\text {int,set,occ }}$ is the set- 
point temperature of the building in normal heating mode $\left({ }^{\circ} \mathrm{C}\right), \theta_{\text {int,set,nocc }}$ is the set-point temperature of the building in reduced heating mode $\left({ }^{\circ} \mathrm{C}\right), \mathrm{f}_{\mathrm{H}, \mathrm{occ}}$ is the fraction of the time step normally heated, $\mathrm{f}_{\mathrm{H} \text {,nocc }}$ is the fraction of the time step with a reduced set-point, $\theta_{\mathrm{e}}$ is the temperature of the external environment $\left({ }^{\circ} \mathrm{C}\right)$ and $t$ is the duration of the calculation step $(\mathrm{Ms})$

As shown in equation 6, the adjusted set-point temperature is calculated in a simplified way as the time weighted average of the set-point temperatures for heating independent of the building’s typology and characteristics. For example (see §3.1.1), assuming a set-point temperature for heating of $20^{\circ} \mathrm{C}$ during school opening hours and a setback temperature of $16^{\circ} \mathrm{C}$ during night-time and weekends, the adjusted monthly set-point temperature is equal to $16.9^{\circ} \mathrm{C}$ on average. However, the results of dynamic simulations reveal different temperatures depending on the energy performance levels ( $U_{\text {mean }}$, air tightness level) or construction types $\left(\mathrm{C}_{\mathrm{m}}\right)$ of the buildings (see $\S 5$ ). Similar results are found in [18] demonstrating for a terraced house that, when realistic heating patterns are implemented, the average dwelling temperatures rise if the energetic quality of the building envelope ( $U_{\text {mean }}$, air tightness level) is enhanced. Nevertheless, these aspects are currently not considered in the adjusted temperature approach of the simplified quasi steady-state calculation method using a fixed indoor temperature at a constant value, independent of outside climate or the insulation or air tightness level of the dwelling.

Secondly, the PASSYS project concluded that the intermittent user profile leads to a mismatch between the heat gains and heat transfer causing a change of the utilized gains [9,17]. EN ISO 13790 implicitly takes into account this phenomenon: the adjusted temperature approach leads to lower indoor temperatures resulting in lower heat losses which in turn leads to a shift towards higher values of the heat-balance ratio $\gamma_{\mathrm{H}}$ and consequently to a 
lower value of the gain utilization factor $\eta_{\mathrm{H}, \mathrm{gn}}$ (Figure 1). Lowering the gain utilization factor implicitly factors in the mismatching between heat gains and heat transfer due to intermittency.

\section{b) CORRECTIONS FOR (LONG) UNOCCUPIED PERIODS}

EN ISO 13790 calculates the heating need during a month which contains a holiday period using the following equation:

$Q_{H, n d, \text { stat }}=\left(1-f_{H, \text { nocc,hol }}\right) * Q_{H, n d, o c c}+f_{H, \text { nocc,hol }} * Q_{H, n d, \text { nocc }}$

where $\mathrm{Q}_{\mathrm{H}, \mathrm{nd}, \text { stat }}$ is the statically calculated energy need for heating assuming for all days of the month the control and thermostat settings of the occupied period $\left(\mathrm{kWh} / \mathrm{m}^{2}\right), \mathrm{Q}_{\mathrm{H}, \mathrm{nd} \text {,nocc }}$ is the statically calculated energy need for heating assuming for all days of the month the control and thermostat settings of the unoccupied period $\left(\mathrm{kWh} / \mathrm{m}^{2}\right)$ and $\mathrm{f}_{\mathrm{H} \text {,nocc,hol }}$ is the fraction of the month which is a holiday period (Table 2)

\section{Insert Table 2}

\section{METHODS}

\subsection{REGRESSION ANALYSIS}

Many characteristics of school buildings (features, occupancy, gains, control) differ significantly compared to residential buildings or offices. As all these characteristics considerably affect the energy need for heating, their impact should be acknowledged in the monthly calculation method and in the determination of the dynamic parameters $\left(\eta_{\mathrm{H}, \mathrm{gn}}, \mathrm{a}_{0}, \tau_{0}\right)$ in particular. Therefore, a regression analysis is performed to obtain a better correlation between the heat-balance ratio $\gamma_{\mathrm{H}}$ and the gain utilization factor $\eta_{\mathrm{H}, \mathrm{gn}}$ than currently used (see 
eq.2 and Fig.1). As it is recommendable to maintain certain uniformity in the static calculation method [7], this study is restricted to the determination of the adapted dynamic parameters $\mathrm{a}_{0}$ and $\tau_{0}$ only. The trend as prescribed in equation 2 is maintained.

The value of the gain utilization factor $\eta_{\mathrm{H}, \mathrm{gn}}$ depends on many parameters. Therefore a large number of calculations is done attempting to cover the whole spectrum of influential parameters using the Monte Carlo analysis technique (MCA) (see §2.2). For each case, the dynamically calculated monthly energy need for heating $\mathrm{Q}_{\mathrm{H}, \mathrm{nd} \text {,dyn }}$ is compared to the results of the simplified monthly calculation method (eq.1). To avoid errors based on the differing assumptions in both models (e.g. simplified models do not take into account solar absorbance of opaque construction parts, generally neglect long wave radiation to the sky,...) both the static and dynamic calculations are performed using the same building energy simulation (BES) program [6]. The study employs the dynamic multi-zone building energy simulation program TRNSYS version 16_1 [16]. The thermal behaviour is studied with a time step of 15 minutes. The simulations are calculated for a typical weather data set for Uccle, Belgium, derived from measured meteorological data between 1996 and 2005 by Meteonorm. The building is modelled as a multi-zone building based on different user profiles and orientations of the rooms, generally correlating to the various types of rooms in the school building $[19,20]$. To accurately evaluate the impact of the intermittency, ventilation schedules, internal heat gains, user's profiles... differing in time and space $[19,20]$ are implemented for both the calculation methods. Only the heating patterns differ. The dynamic calculations are performed implementing realistic heating patterns. The indoor operative temperatures fluctuate freely depending on the boundary conditions (set-point temperatures, user's profile,...) and building characteristics (see Fig.7 and 8). For the static calculations on the other hand, the simulations 
are performed implementing the adjusted temperature approach as described in $§ 1.2 \mathrm{a}$. In order to maintain the monthly mean indoor operative temperature equal to the time weighted average of the set-point temperatures for heating as used in the quasi steady-state calculation method, the operative temperature is set constant to $20^{\circ} \mathrm{C}$ during the school opening hours and to the setback temperature when the school is closed (f.i. night-time, weekends).

As aforementioned, for the regression analysis, the dynamically calculated monthly energy need for heating is compared to the results of the simplified monthly calculation method. To obtain a more accurate value for the gain utilization factor $\eta_{\mathrm{H}, \mathrm{gn} \text {,adap }}$ the difference $\mathrm{x}$ between the dynamically calculated energy need for heating $\mathrm{Q}_{\mathrm{H}, \mathrm{nd} \text {,dyn }}$ and the statically calculated energy need for heating $\mathrm{Q}_{\mathrm{H}, \mathrm{nd}, \text { stat }}$ must be minimized by varying the dynamic parameters $\mathrm{a}_{0}$ and $\tau_{0}$.

$x=\sum\left(Q_{H, n d, d y n}-Q_{H, n d, s t a t}\right)^{2}$

The static energy need for heating is calculated using equation 1 with the monthly heat gains $\mathrm{Q}_{\mathrm{H}, \mathrm{gn}}$ and monthly heat transfer $\mathrm{Q}_{\mathrm{H}, \mathrm{ht}}$ calculated using the following equations:

$Q_{H, h t}=Q_{t r}+Q_{v e}(9) \quad$ and $Q_{H, g n}=Q_{i n t}+Q_{s o l}(10)$

where $\mathrm{Q}_{\mathrm{tr}}$ is the statically calculated monthly heat transfer by transmission $\left(\mathrm{kWh} / \mathrm{m}^{2}\right), \mathrm{Q}_{\mathrm{ve}}$ is the statically calculated monthly heat transfer by ventilation $\left(\mathrm{kWh} / \mathrm{m}^{2}\right), \mathrm{Q}_{\text {int }}$ is the statically calculated sum of monthly internal heat gains $\left(\mathrm{kWh} / \mathrm{m}^{2}\right)$ and $\mathrm{Q}_{\text {sol }}$ is the statically calculated sum of monthly solar heat gains $\left(\mathrm{kWh} / \mathrm{m}^{2}\right)$ 
The total heat transfer by transmission $\mathrm{Q}_{\mathrm{tr}}$ is calculated as the sum of the steady-state transmission losses of all the walls and windows in every zone. These are calculated as the subtraction of the monthly energy coming from the inside outer wall surfaces (including convective heat transfer to the air and long wave radiation to other surfaces) and the absorbed (or transmitted) energy at inside surfaces (including solar gains, radiative heat, internal radiative gains and wall gains, except long wave radiation exchange with other walls). The ventilation losses $Q_{v e}$ are calculated by summing the sensible infiltration and ventilation energy losses of all the zones. The internal heat gains $\mathrm{Q}_{\text {int }}$ are the sum of the internal convective and radiative gains. Lastly, the solar heat gains $\mathrm{Q}_{\text {sol }}$ consist of the sum of all absorbed solar radiation at the inside surfaces of all zones.

In case the monthly heat gains $\mathrm{Q}_{\mathrm{H}, \mathrm{gn}}$ and heat transfer $\mathrm{Q}_{\mathrm{H}, \mathrm{ht}}$ would be calculated based on the results of the dynamic instead of the static calculations, the effect of the undesirable increase of the internal temperature above the set-point would be factored in the calculation of the gain utilization factor. Allowing the indoor temperature to vary above the set-point leads to higher heat transfers $\mathrm{Q}_{\mathrm{H}, \mathrm{ht}}$ and therefore to higher gain utilization factors. This is however in conflict with the basic principle of the quasi steady-state method (see $§ 1.1$ ), especially if the adapted gain utilization factors is used in combination with the adjusted temperature approach as described in $§ 1.2$.a.

Furthermore, long unoccupied periods (holidays) are excluded for the regression analysis as prescribed in EN ISO 13790 (see $§ 1.2 . b$ ). In case holidays would be included, additional differentiation of the monthly gain utilization factors $\eta_{\mathrm{H}, \mathrm{gn}}$ for certain heat-balance ratios 
would occur: the more holidays a month counts, the more the gain utilization factor deviates from the results in case no holidays are included. Figure 2 shows the results for $\eta_{\mathrm{H}, \mathrm{gn}}$ in function of $\gamma_{\mathrm{H}}$ for the month April and October which count twelve and two holidays, respectively.

\section{Insert Figure 2}

While including the holidays, the gain utilization factor of October is lowered by 0.03 or $4.56 \%$ on average. In April on the other hand, the gain utilization factor is on average 0.10 or $17.28 \%$ lower. Combining the effect of the implementation of a monthly varying number of holidays with the fact that, although the results of the quasi steady-state calculation method on an annual time bases are satisfactory, the results for individual months close to the beginning and the end of the heating season can have large relative errors [6], the impact of an equal number of holidays is assessed differently month by month. This affects the results of the regression analysis, the determination of the dynamic parameters $\mathrm{a}_{0}$ and $\tau_{0}$ and thus the accuracy of the gain utilization factor. Therefore, in conformity with EN ISO 13790, the long unoccupied periods are taken into account using equation 7.

As the opening hours of schools are limited and thus the time fraction of the use of schools is small ( $f_{\text {occ,monthly }}=23 \%$ on average, without holidays $)$, the monthly averaged heat gains $Q_{\mathrm{H}, \mathrm{gn}}$ are generally small compared to the monthly averaged heat transfer $\mathrm{Q}_{\mathrm{H} \text {,ht }}$ which results in low values for the monthly heat-balance ratio $\gamma_{\mathrm{H}}$. In this case the value for the gain utilization factor $\eta_{\mathrm{H}, \mathrm{gn} \text {,stat }}$ calculated using equation 1 becomes almost indeterminable. The two numerators are almost equal, while the denominator is small with the result that the outcome 
of the regression analysis becomes unreliable. A method of avoiding this mathematical problem is described in EN ISO 13790: the regression analysis should not be performed on the gain utilization factor $\eta_{\mathrm{H}, \mathrm{gn}}$ but on the relative overheating $\mathrm{dT}_{\mathrm{R}, \mathrm{H}}$

$d T_{R, H}=\frac{Q_{H, n d, d y n}+Q_{H, g n}}{Q_{H, h t}}=\left(1-\eta_{H, g n}\right) * \gamma_{H}+1$

This quantity is mathematically more robust, also for low values of the heat gains. To obtain a more accurate value for the gain utilization factor $\eta_{\mathrm{H}, \mathrm{gn} \text {,adap }}$ the difference $\mathrm{x}$ between the original relative overheating $\mathrm{dT}_{\mathrm{R}, \mathrm{H}, \text { org }}$ and the adapted relative overheating $\mathrm{dT}_{\mathrm{R}, \mathrm{H} \text {,adap }}$ must be minimized by varying the dynamic parameters $\mathrm{a}_{0}$ and $\tau_{0}$.

$x=\sum\left(d T_{R, H, o r g}-d T_{R, H, a d a p}\right)^{2}$

where $d T_{R, H, \text { org }}=\left(1-\eta_{H, \text { gn,org }}\right) * \gamma_{H}+1(13)$ and $d T_{R, H, \text { calc }}=\left(1-\eta_{H, \text { gn opt }}\right) * \gamma_{H}+1$

The regression analysis and the determination of the values for $\mathrm{a}_{0}$ and $\tau_{0}$ is performed using the Evolutionary Solver of MS Excel [21].

\subsection{BUILDING SIMULATION MODEL}

This section starts with the description of the school building and the main characteristics.

Afterwards, the influential parameters affecting the gain utilization factor $\eta_{\mathrm{H}, \mathrm{gn}}$ are described (f.i. the thermal capacity, global insulation level, the solar gains, the occupant density and 
related ventilation rates and internal heat gains, the air tightness level and the characteristics of the installed heating and ventilation system).

\subsubsection{BUILDING CHARACTERISTICS}

This study focusses on elementary school buildings in particular, since they are considered to have reasonably steady occupancy profiles and activities compared to other school typologies (secondary education, general -> vocational). A reference school building, representing a current typical Flemish school building, is used for the calculations [22]. Figure 3 shows the school prototype model used as a reference for elementary education. The reference case consists of two floors including the most common rooms: class rooms $\left(41 \%\right.$-> $\left.846 \mathrm{~m}^{2}\right)$, a teacher's room $\left(3 \%->63 \mathrm{~m}^{2}\right)$, offices $\left(5 \%->106 \mathrm{~m}^{2}\right)$, a gym $\left(13 \%->265 \mathrm{~m}^{2}\right)$, a canteen and kitchen $\left(11 \%\right.$-> $\left.236 \mathrm{~m}^{2}\right)$, circulation zones, sanitary and storage rooms $\left(26 \%\right.$-> $\left.543 \mathrm{~m}^{2}\right)$. The total heated volume equals $6570 \mathrm{~m}^{3}$ while the heat loss surface $\mathrm{A}_{\mathrm{T}}$ equals $3694 \mathrm{~m}^{2}$, leading to a compactness level of 1.78 . The general building data is summarized in Table 3 .

\section{Insert Figure 3}

For the dynamic simulations in TRNSYS the building has been subdivided into seven different zones. The zone 'class_F' $\left(1571 \mathrm{~m}^{3}\right)$ comprises all class rooms at the front of the building. The zone 'class_B' $\left(797 \mathrm{~m}^{3}\right)$ contains all class rooms at the back of the building. The rest of the building consists of a canteen/kitchen $\left(659 \mathrm{~m}^{3}\right)$, a gym $\left(1553 \mathrm{~m}^{3}\right)$, offices (298 $\left.\mathrm{m}^{3}\right)$, a teachers' room $\left(177 \mathrm{~m}^{3}\right)$ and space for circulation, sanitary and storage $\left(1515 \mathrm{~m}^{3}\right)$ as shown in Figure 3.

Insert Table 3 
A set of boundary conditions representative for the specific school characteristics, has been developed previously by the authors $[19,20]$. For each school zone specific internal heat gains (IHG) from lighting equipment, appliances and occupants (see Table 4) and user's profiles are implemented.

\section{Insert Table 4}

\subsubsection{SYSTEM CHARACTERISTICS}

The school is equipped with a balanced mechanical ventilation system. The ventilation air is preheated by air-to-air heat exchangers with an efficiency of $75 \%$. The supply of air is provided into the occupied rooms (class rooms, gyms, offices, ...). The operation of the fans is controlled by a time schedule according to the user's profile. Due to the intermittent ventilation schedule EN 15251 requires that each room is pre-ventilated for one hour prior to the school start. Two air changes per hour are required to guarantee a sufficient indoor air quality at the start of a school day. The set-point temperature for heating during school opening hours is set to be $20^{\circ} \mathrm{C}$ for the whole building $[19,20]$. No interzonal temperature differences are assumed. During nights and weekends a setback of the temperature will be considered.

\subsection{DETERMINATION OF THE DYNAMIC PARAMETERS $\mathbf{a}_{0}$ AND $\tau_{0}$ : MONTE Carlo analysis}

The value of the gain utilization factor $\eta_{\mathrm{H}, \mathrm{gn}}$ depends on many parameters. Therefore a large number of calculations must be done attempting to cover the whole spectrum of influential parameters. In this study, the Monte Carlo analysis technique (MCA) is used varying the thermal capacity, global insulation level, the solar gains, the occupant density and related ventilation rates and internal heat gains, the air tightness level and the characteristics of the 
installed heating and ventilation system. Firstly, values are set for each of the varying parameters. Many studies can be found in which the type of distribution for certain typical parameters in building models is defined. Unfortunately, empirical and experimental information about realistic ranges and distributions of most of the aforementioned boundary conditions (set-point temperatures, heating patterns, user's profiles,...) for school buildings is rare. As the MCA technique is not used for a profound sensitivity and uncertainty analysis but to consider the broad spectrum of aforementioned parameters, a pragmatic approach is used: the magnitude and probability distribution of each input parameter used for the MCA are based on literature. Without specific information, a uniform distribution is typically used with a large parameter range [24] (§2.2.1-7). Secondly, samples are generated. According to Saltelli et al., fairly robust results can be obtained using the Latin Hypercube sampling technique (LHC) [25]. This method is a particular case of stratified sampling ensuring that the sampling is representative for the whole range of variability [25]. The Monte Carlo method usually requires 60 - 80 simulations regardless of the number of input parameters [26]. For this study a sample of 80 is used.

\subsubsection{THERMAL CAPACITY}

To evaluate the effect of thermal inertia, the structure is altered from very light to heavy (Table 5). The materials used for wall and roof constructions are changed (see Table 6). The internal thermal inertia, $\mathrm{C}_{\mathrm{m}}$, of each case is calculated using the simplified method EN 13786 annex A, suitable for the determination of dynamic thermal properties required for the estimation of energy use.

$C_{m}=\sum A_{j} \kappa_{j}$ 
where $\kappa_{\mathrm{j}}$ is the internal heat capacity per area of the building element $\mathrm{j}\left(\mathrm{J} /\left(\mathrm{m}^{2} \cdot \mathrm{K}\right)\right)$ and $\mathrm{A}_{\mathrm{j}}$ is the area of the element $\mathrm{j}\left(\mathrm{m}^{2}\right)$

with $\kappa_{j}=\sum \rho_{i} * c_{i} * d_{i}$

where $\rho_{i}$ is the density of material $i\left(\mathrm{~kg} / \mathrm{m}^{3}\right), c_{i}$ is the specific heat capacity of material $i$ $\left(\mathrm{J} /(\mathrm{kg} . \mathrm{K})\right.$ and $\mathrm{d}_{\mathrm{i}}$ is the thickness of the material $\mathrm{i}(\mathrm{m})$

\section{Insert Table 5}

\subsubsection{GLOBAL INSULATION LEVEL}

The insulation quality of the floor, roof, external walls and windows vary according to a uniform distribution curve. The minimum thicknesses of the insulation materials correspond to the minimum legal required values [2]. The maximum insulation levels are based on the insulation levels of various realized passive school projects [22]. Table 7 shows the varying thicknesses of insulation materials. For each case, the thickness of the insulation materials is chosen so that the U-values of the lightweight and heavyweight envelope parts are equal. The global U-value of the building, $\mathrm{U}_{\text {mean, }}$ varies from $0.17 \mathrm{~W} /\left(\mathrm{m}^{2} . \mathrm{K}\right)$ to $0.43 \mathrm{~W} /\left(\mathrm{m}^{2} . \mathrm{K}\right)$.

Insert Table 6

Insert Table 7 


\subsubsection{SOLAR HEAT GAINS}

To vary the solar heat gains, two different shading device control strategies $\left(\mathrm{q}_{\mathrm{control}}=\right.$ threshold of total solar radiation on the surface when blinds are closed or opened) for the retractable shading devices are implemented

- $\quad \mathrm{q}_{\text {control }}=300 \mathrm{~W} / \mathrm{m}^{2}$

- $\quad \mathrm{q}_{\text {control }}=150 \mathrm{~W} / \mathrm{m}^{2}$

In case the blinds are closed, $70 \%$ of the total solar radiation on the shaded surface is blocked.

Additionally, the glazed surface area, $\xi$, expressed by the ratio between the window area and floor area, is varied: $10 \%, 20 \%$ or $30 \%$.

\subsubsection{OCCUPANT DENSITY}

Variations of the occupant density rate affect both the internal heat gains and the ventilation rates. The occupant density for class rooms is calculated as the mean available surface area per pupil ( $\mathrm{m}^{2} /$ pers). The cumulative lognormal distribution function for the occupant density in primary schools is determined from previous research [28] and shown in Figure 4.

Insert Figure 4

\subsubsection{ORIENTATION}

The impact of orientation is evaluated by turning the building. The azimuths of the surfaces or axis' of rotation are varied according to a uniform distribution curve $\left(0^{\circ}-360^{\circ}\right)$. 


\subsubsection{AIR TIGHTNESS LEVEL}

The air tightness level varies according to a uniform distribution curve. The maximum $\mathrm{n}_{50}$ (vol/h) value correspond to two air changes per hour. The minimum air tightness level is equal to the performance criteria as set for passive school buildings $n_{50}=0.6 \mathrm{vol} / \mathrm{h}$.

\subsubsection{HEATING AND VENTILATION}

The efficiency of the heating system links the building's energy need to the building energy use. The overall efficiency is determined by the production losses, distribution losses, etc. In this study the production and distribution losses are not considered, however the influences of the emission system and the control strategy are. To assess the impact of the emission system, the convective fraction of the heating system is varied from fully convectional $(\mathrm{rrad}=0)$ to radiators using both convective and radiative effects $(\mathrm{rrad}=0.4)$. To assess the impact of the control strategy, various heating scenarios are taken into account. All the simulations are done twice: once as a continuously heated case with a constant set-point temperature for heating equal to $20^{\circ} \mathrm{C}$ and again as a discontinuously heated case with a setback temperature of respectively $15^{\circ} \mathrm{C}, 16^{\circ} \mathrm{C}$ and $17^{\circ} \mathrm{C}$. Finally, to assess the impact of ventilation the simulations are repeated for ventilation rates uniformly varying between the lowest $\left(22 \mathrm{~m}^{3} /(\right.$ h.pers $\left.)\right)$ rate according to the a moderate indoor air quality level (IDA 3) and the highest rate (54 $\mathrm{m}^{3} /($ h.pers)) according a medium indoor air quality level (IDA2) [29]. No inter- and interzonal airflows are taken considered.

\section{RESUlTS}

This paper tries to improve the accuracy of the monthly calculation model in particular for schools buildings: the gain utilization factor $\eta_{\mathrm{H}, \mathrm{gn}}$ and the parameters $\mathrm{a}_{0}$ and $\tau_{0}$ are specifically 
determined for the Flemish climate and the typical characteristics and user's data of school buildings.

\subsection{DETERMINATION OF THE CORRELATION BETWEEN $\boldsymbol{\eta}_{\mathrm{H}, \mathrm{GN}}$ AND $\boldsymbol{\gamma}_{\mathrm{H}}$}

A regression analysis is performed to determine the correlation between the parameters $\gamma_{\mathrm{H}}$ and $\eta_{\mathrm{H}, \mathrm{gn}}$ comparing the dynamically calculated energy need for heating $\mathrm{Q}_{\mathrm{H} \text {,nd,dyn }}$ to the results of the simplified monthly calculation method $\mathrm{Q}_{\mathrm{H}, \mathrm{nd}, \mathrm{stat}}$. Results are shown in Figure 5 and 6. Figure 5 demonstrates the results of the monthly gain utilization factor $\eta_{\mathrm{H}, \mathrm{gn}}$ as function of the heat-balance ratio $\gamma_{\mathrm{H}}$ for the four classifications of thermal capacity of the building: heavy, medium, light and very light as a grey zone between the minimum and maximum results. The dashed lines represent the average results. For comparison, the results of the monthly gain utilization factors as used in EN ISO 13790 for the quasi steady-state method (eq. 2) are shown for various time constants of the building $(\tau=150$ (averaged value for the school building with a high thermal capacity), $\tau=85$ (medium), $\tau=60$ (light), and $\tau=40$ (very light)). To visualize in particular the influence of the various thermal capacities, all results are recapitulated in Figure 6. The averages of the results of the monthly gain utilization factor $\eta_{\mathrm{H}, \mathrm{gn}}$ as function of heat-balance ratio $\gamma_{\mathrm{H}}$ for the four classifications of thermal capacity of the building are demonstrated.

\section{Insert Figure 5}

\section{Insert Figure 6}

The results show that the gain utilization factor for schools with an intermittent use is generally lower than the values obtained with EN ISO 13790. This indicates that due to the intermittency the available heat gains are less effectively used compared to continuously 
heated buildings. Similar results are obtained in [30] concluding that on average lower gain utilization factors are found for cases implementing a setback temperature. Furthermore, two other significant effects are observed. Firstly, for high heat gains and thus high heat-balance ratios $\left(\gamma_{\mathrm{H}}>0.7\right)$, the thermal capacity's impact is limited when compared to continuously heated buildings (full lines). Secondly, for low heat-balance ratios $\left(\gamma_{\mathrm{H}}<0.7\right)$, unlike the expected trend described in equation 2, the gain utilization factor decreases with increasing thermal inertia. The aforementioned effects are studied more in detail focussing first on the results for $\gamma_{\mathrm{H}}>0.7$. In conformity with EN ISO 13790, the gain utilization factor depends on the time constant of the building $\tau$. However, compared to continuously heated buildings, the difference between the results for high, medium, light and very light buildings is limited indicating that the building capacity has a smaller effect on the gain utilization factor. To analyse the effect of the thermal capacity on the energy need for heating specifically, the results of the dynamic simulations for the zone 'class_B' for a setback temperature of $3 \mathrm{~K}$ during nights and weekends for a very well insulated building $\left(\mathrm{U}_{\text {mean }}=0.17 \mathrm{~W} /\left(\mathrm{m}^{2} \cdot \mathrm{K}\right)\right)$ are shown (Fig.7). Figure 7 shows the air, operative and mean surface temperature of the zone 'class_B', for a light and heavy building on a regular school day in winter (Tuesday $6^{\text {th }}$ of February). Figure 8 shows the operative indoor temperature of the zone 'class_B', for a light and heavy building model and the corresponding energy need for heating for a regular school week in winter (Monday $5^{\text {th }}-$ Sunday $12^{\text {th }}$ of February).

\section{Insert Figure 7}

\section{Insert Figure 8}


Both figures demonstrate the damping effect of the thermal mass on the temperature drop during absence: temperatures decrease slower in heavy school buildings. The operative temperature in zone 'class_B' at the beginning of the school day (Fig. 7) has dropped from $21.5^{\circ} \mathrm{C}$ to $18^{\circ} \mathrm{C}$ for the light building. The temperature of the heavy building is at that moment still $18.5^{\circ} \mathrm{C}$. For heavy structures, the lowered set-point temperature for heating, $\theta_{\mathrm{i}, \text { heat,min }}=$ $17^{\circ} \mathrm{C}$, is not reached during the whole week so no heating is required during nights (Fig. 7) and weekends (Fig. 8). On the other hand, during the day, the energy need for heating of the heavy structures is usually larger as more constructive mass requires heating. Both aforementioned points reveal why the effect of highly capacitive buildings is less positive regarding the use of stored heat gains compared to continuously heated buildings for buildings with high heat-balance ratios $\gamma_{\mathrm{H}}$.

For heat-balance ratios smaller than 0.7, a different trend is noticed. According to EN ISO 13790, for low heat-balance ratios, most of the available heat gains can be used to cover the heat losses resulting in gain utilization factors near to one for all thermal capacities (see Fig. 1, part I). However, as shown in Figure 5 and 6, the application of a setback temperature for heating lowers the gain utilization factor for low heat-balance ratios. This finding is more pronounced for heavy buildings. As mentioned in $\$ 2.1$ the building energy need for heating is calculated as the difference between the heat losses and the usable part of the available heat gains (eq.1). Part of the gains will be used immediately, the remainder will be temporarily stored in the thermal mass and will be emitted at a later time step. The higher the thermal capacity, the more mass there is available for storage so the higher values for the gain utilization factors are to be expected. However, the useful effect of the temporary storage 
depends on the user's profile of the building as well. In buildings with an intermittent use, the better accumulation of available heat gains in heavy weight constructions leads to a much slower cool down process resulting in higher internal temperatures and thus in higher transmission heat losses during the night $[11,17]$. Instead of correcting the set-point temperature and thus adapting the heat losses depending on the efficacy of the setback, the 'overheating' results in a reduction of the gain utilization factor as shown in Figure 5 and 6. This effect is clearest in cases where the heat losses are big and hence especially noticed for low heat-balance ratios. Similar results are found in [30] for buildings with a setback temperature during night and weekends.

\subsection{DETERMINATION OF $\mathbf{a}_{0}$ AND $\tau_{0}$}

In conformity with the results found in previous researches $[9,10,17]$, the determination of the gain utilization factor $\eta_{\mathrm{H}, \mathrm{gn}}$ and in particular the dynamic parameters $\mathrm{a}_{0}$ and $\tau_{0}$ focuses on the heat-balance ratio $\gamma_{\mathrm{H}}$ and the time constant of the building $\tau$. To maintain uniformity in the static calculation method the trend as prescribed in equation 2 is chosen a starting point. As discussed in $\S 2.1$, it is better to perform the regression analysis on the relative overheating $\mathrm{dT}_{\mathrm{R}, \mathrm{H}}$ instead of the energy need for heating $\mathrm{Q}_{\mathrm{H}, \mathrm{nd}}$. For the regression analysis, the difference between the original relative overheating $\mathrm{d}_{\mathrm{TR}, \mathrm{H}, \text { org }}$ and the adapted relative overheating $\mathrm{d}_{\mathrm{TR}, \mathrm{H} \text {,adap }}$ is minimized by varying the dynamic parameters $\mathrm{a}_{0}$ and $\tau_{0}$ (see eq. 12 ). A minimum is found for the dynamic parameters $\mathrm{a}_{0}=1.4$ and $\tau_{0}=185$.

As the results of the quasi steady-state monthly calculation for individual months close to the beginning and the end of the heating season can have large relative errors [6], results are further discussed on an annual instead of a monthly time basis. The results of the regression analysis are presented in Table 8 showing the maximum, mean and minimum value of the 
dynamically $\left(\mathrm{Q}_{\mathrm{H}, \mathrm{nd}, \mathrm{dyn}}\right)$ and statically $\left(\mathrm{Q}_{\mathrm{H}, \mathrm{nd}, \text { org }}\right.$ and $\left.\mathrm{Q}_{\mathrm{H}, \mathrm{nd}, \text { adap }}\right)$ calculated annual energy need for heating.

\section{Insert Table 8}

The absolute difference between the dynamically $\left(\mathrm{Q}_{\mathrm{H}, \mathrm{nd} \text {,dyn }}\right)$ and statically $\left(\mathrm{Q}_{\mathrm{H}, \mathrm{nd} \text {,stat }}\right)$ calculated annual energy need for heating using respectively the original and adapted dynamic parameters $\mathrm{a}_{0}$ and $\tau_{0}$ is shown in Figure 9 showing a clear reduction of the absolute difference using the adapted values of $\mathrm{a}_{0}$ and $\tau_{0}$.

\section{Insert Figure 9}

Comparing the dynamic and the static annual energy need for heating, the average absolute difference between the dynamic and static calculations is limited to $1.41 \mathrm{kWh} /\left(\mathrm{m}^{2} . \mathrm{a}\right)$ rather than $5.39 \mathrm{kWh} /\left(\mathrm{m}^{2}\right.$.a). Furthermore, the average relative difference, given as the difference in calculated monthly energy needs for heating and expressed as a percentage of the dynamic annual energy need for heating, is lowered by $2.21 \%$. The results are presented in Table 9.

\section{Insert Table 9}

Finally, the impact of the implementation of the adapted dynamic parameters on the gain utilization factor in relation to the heat-balance ratio is shown in Figure 10.

\section{Insert Figure 10}

As described in $\$ 4.1$, generally lower gain utilization factors are found resulting in lower curves (full line) compared to the continuously heated buildings (dotted lines). Additionally, as a result of the smaller effect of the thermal capacity, the curves are situated closer together. 


\section{Discussion}

Even after adapting the gain utilization factor $\eta_{\mathrm{H}, \mathrm{gn}}$ and dynamic parameters $\mathrm{a}_{0}$ and $\tau_{0}$ specifically to the Flemish climate and the typical characteristics and user's data of school buildings, still important discrepancies remain between the results of the dynamic and quasi steady-state calculations. This can be explained by two reasons. Firstly, the choice to maintain the original trend as set in the PASSYS project $[9,10]$ and used in EN ISO 13790 (eq.2) makes it impossible to account for the drop of the gain utilization factor for low heat-balance ratios. Neglecting this phenomenon results in a general overestimation of the gain utilization factor for low heat-balance ratios and thus an underestimation of the energy need for heating for these specific cases. Secondly, as mentioned in §1.2.a, intermittent heating is considered as continuous heating with an adjusted set-point temperature, $\theta_{\text {int,adj,st }}$ using a fixed indoor temperature at a constant value, independent of outside climate or the insulation or air tightness level of the dwelling (eq.6). For the static calculations ( $\left.\mathrm{Q}_{\mathrm{H}, \mathrm{ht}}\right)$, the simulations are performed using this adjusted temperature approach: the operative temperature is set constant to $20^{\circ} \mathrm{C}$ during school opening hours and to the setback temperature during night-time and weekends. For February, this results in an monthly average temperature equal to $16.2^{\circ} \mathrm{C}$, $16.9^{\circ} \mathrm{C}$ and $17.7^{\circ} \mathrm{C}$ for a setback temperature of $15^{\circ} \mathrm{C}, 16^{\circ} \mathrm{C}$ and $17^{\circ} \mathrm{C}$ respectively, independent of the typology and characteristics of the building. However, the results of dynamic simulations reveal differing mean temperatures depending on the insulation level $\left(\mathrm{U}_{\text {mean }}\right)$, air tightness level $\left(\mathrm{n}_{50}\right)$ or construction type $\left(\mathrm{C}_{\mathrm{m}}\right)$. Figure 11 illustrates this for a school building with a heavy $\left(\mathrm{C}_{\mathrm{m}}=7.27 * 10^{8} \mathrm{~J} / \mathrm{K}\right)$ and a light structure $\left(\mathrm{C}_{\mathrm{m}}=3.28 * 108 \mathrm{~J} / \mathrm{K}\right)$. Simulations are done twice, once for a building with a global insulation level according to the EPBD requirements (2012) of $\mathrm{U}_{\text {mean }}=0.43 \mathrm{~W} /\left(\mathrm{m}^{2} . \mathrm{K}\right)$ (reference building, full line) and once for a global insulation level of $\mathrm{U}_{\text {mean }}=0.17 \mathrm{~W} /\left(\mathrm{m}^{2} . \mathrm{K}\right)$ (passive building, dashed line). The 
setback temperature equals $16^{\circ} \mathrm{C}$ in both cases. The daily mean indoor temperature is calculated for each case. The results on a monthly time basis are summarized in Table 10 .

\section{Insert Table 10}

To illustrate the effect on the results of the monthly calculation method more in detail some additional simulations are done, once again for a reference and a passive building. The same parameters as mentioned in $\$ 2.2$ are varied but the sample of calculations is limited to five case only for each of the thermal capacities.

As shown in Figure 11, the accuracy of the quasi steady-state calculation method depends of the energy performance level of the building: a better agreement is found for the reference building than for the passive building. Therefore, to conclude, the quasi steady-state calculation method remains questionable especially for very well insulated and air tight buildings. Similar results are found by Jokisalo and Kurnitski [13], stating that the simplified monthly calculation method of EN ISO 13790 should not be used for office buildings with an intermittent use.

\section{Insert Figure 11}

\section{CONCLUSION}

The quasi steady-state single zone calculation method on a monthly time base is commonly used for performance compliance checking giving a simple and traceable indication of the energy performance of a building. However, due to the simplicity of the method, dynamic effects (e.g. climatic conditions, user behavior, time schedules, ...) are only considered in a simplified way by time weighted averaged values and dynamic factors. The current form of the quasi steady-state method is determined in the PASSYS project for residential buildings. 
However, as the typology and characteristics of buildings considerably affect the energy need for heating, their impact must be specifically acknowledged in the monthly calculation method. Therefore, this paper tries to improve the accuracy of the monthly calculation model in particular for schools buildings by adapting the gain utilization factor $\eta_{\mathrm{H}, \mathrm{gn}}$ and the dynamic parameters $\mathrm{a}_{0}$ and $\tau_{0}$ specifically for Flemish school buildings. Using regression analysis, better results are found for the static energy need for heating using the dynamic parameters $a_{0}$ $=1.4$ and $\tau_{0}=185$ instead of $\mathrm{a}_{0}=1$ and $\tau_{0}=15$. Comparing the dynamic and the static results, the average absolute difference between the dynamic and static calculations is limited to 1.41 $\mathrm{kWh} /\left(\mathrm{m}^{2}\right.$.a) using the new dynamic parameters rather than $5.39 \mathrm{kWh} /\left(\mathrm{m}^{2}\right.$.a). However, even after optimization distinct discrepancies remain between the dynamically and statically calculated energy need for heating. Especially for very well insulated and air tight buildings, the accuracy of the current quasi steady-state method for school buildings remains unreliable. This is mainly because the accuracy of the quasi steady-state calculations is simultaneously determined by the value of the gain utilization factor and by the assessment of the adjusted set-point temperature. For buildings with an intermittent use, the temperature is set back while absent. As mentioned in 1.2., this is accounted for by the adjusted temperature approach or the implementation of a time weighted average set-point temperature independent of the building's typology and characteristics in the static calculation method. Dynamic simulations however revealed rising average temperatures when insulation and air tightness level of the building envelope are enhanced. These aspects are currently not considered in the adjusted temperature approach. Therefore, an additional parameter study must be performed, following this research, to determine the correction of the set-point temperature in cases of a setback during night-time and weekends so that the simplified monthly calculation method of EN 13790 can be used properly for non-residential buildings. 


\section{REFERENCE}

[1] IEA, Energy Technology Perspectives 2008: Scenarios and strategies to 2050. International Energy Agency, 2008

[2] EPBD, Directive 2002/91/EC of the European Parliament and of the Council of 16 December 2002 on the energy performance of buildings

[3] Kaan, H., PEP project - Passive Houses Worldwide: International Developments, 10th International Passive house conference, Hanover, Germany (May 19-20, 2006) pp.299308

[4] Mlecnik, E., PEP project - Promotion of Passive Houses: from estimating the energy saving potential to the implementation of financial stimuli, 10th International Passive house conference, Hanover, Germany (May 19-20, 2006) pp.159-164

[5] EPB, 2005, Calculation Method for the Characteristic Annual Primary Energy Consumption in Tertiary Buildings, Annex II to the Flemish EPB-legislation.

[6] EN ISO 13790:2007, Energy performance of buildings - Calculation of energy use for space heating and cooling, TC 163/SC 2, ISO, Geneva (2007)

[7] Van Dijk, H.A.L., Spiekman, M.E. and De Wilde, P.A., Monthly method for calculating energy performance in the context of European building regulations, Proceedings of the 9th International IBPSA Conference, Montréal, Canada (August 15-18, 2005), pp. 255262

[8] Van Dijk, H.A.L., Spiekman, M.E., Energy Performance of Buildings; Outline for Harmonised EP Procedures. Final report of EU ENPER project, Task B6. Contract 
SAVE 4. 1031/C/00-018 TNO Building and Construction Research, Delft, The Netherlands (June 29, 2004) (http://www.enper.org)

[9] PASSYS, Final Report of the Simplified Design Tool Subgroup, Commission of the European Communities, Directorate General XII, EUR 12998 EN, Brussels (1989)

[10] PASSYS-II, Research Report of the Simplified Design Tool Subgroup, Commission of the European Communities, Directorate General XII, Contract JOUE-CT90-0022, Brussels, September (1993)

[11] Loga, T., Kahlert,C., Laidig,M., Lude,G., Räumlich und zeitlich eingeschränkte Beheizung: Korrekturfaktoren zur Berücksichtigung in stationären Energiebilanzverfahren, IWU/ebök, Darmstadt, Germany (1999)

[12] Kokogiannakis, G., Support for the Integration of Simulation in the European Energy Performance of Buildings Directive, PhD, University of Strathclyde, Glasgow, Scotland (December 2008)

[13] Jokisalo, J., Kurnitski,J., Performance of EN ISO 13790 utilisation factor heat demand calculation method in a cold climate. Energy and Buildings 39 (2007) pp. 236-247

[14] Corrado,V., Fabrizio,E., A simplified calculation method of the annual energy use for space heating and cooling : Assessment of the dynamic parameters for the Italian building stock and climate. in: P. Fazio, H. Ge, J. Rao, G. Desmarais (Eds.), Research in Building Physics and Building Engineering (2006) pp. 645-654

[15] Corrado, V., Fabrizio,E., Assessment of building cooling energy need through a quasisteady state model : Simplified correlation for gain-loss mismatch, Energy and Buildings 39 (2007) pp. 569-579 
[16] S.A.Klein, et al., TRNSYS-Reference Manual, Solar Energy Laboratory, University of Wisconsin-Madison, Madison, WI,USA (2000)

[17] Van Dijk, H.A.L., Arkesteijn, C.A.M., Windows and space heating requirements: parameter studies leading to a simplified calculation method, IEA ECBCS Implementing agreement project “Annex XII, Windows and Fenestration”, Delft, The Netherlands (December 1987)

[18] Deurinck, M., Saelens, D., Roels, S., Assessment of the physical part of the temperature takeback for residential retrofits, Energy and Buildings 52 (2012) pp.112-121

[19] Wauman,B. et al., Implementation of realistic boundary conditions - Analysis of their effect on the net annual heating demand in passive schools. Proceedings of the 1st Central European Symposium on building physics, Cracow, Poland (September,13-15, 2010), pp.455-462

[20] Wauman,B., et al., Determination of boundary conditions for passive schools : impact on heating and cooling demand. Tagungsband zur 14. Internationalen Passivhaustagung, Dresden, Germany, (May 28-29, 2010), pp.239-244

[21] Premium solver user guide

[22] Wauman, B., Representative type model approach for passive school buildings, internal report, Ghent, Belgium (2012)

[23] EN 15251:2007, Indoor environmental input assessment of energy performance of buildings addressing indoor air quality, thermal environment, lightning and acoustics

[24] Eisenhower, B., O’Neill, Z., Narayanan, S., Fonoberov, V.A., Mezi, I., Comparative study on uncertainty propagation in high performance building design. Proceedings of 
12th Conference of International Building Performance Simulation Association, Sydney, Australia, (November $14-16^{\text {th }}, 2011$ ), pp. 2785-2792

[25] Saltelli, A., Chan, K., Scott, E.M., Eds,Sensitivity Analysis, Chichester, UK, John Wiley and Sons (2000)

[26] Lomas, K.J., Eppel, H., Sensitivity analysis techniques for building thermal simulation programs, Energy and Building 19 (1992) pp.21-44

[27] EN 13786:2008, Thermal performance of building components - Dynamic thermal characteristics - Calculation methods

[28] Wauman, B., Breesch, H., Saelens, D., Implementation of realistic boundary conditions - Analysis of their effect on the net annual heating demand in passive schools. Proceedings of the 9th Nordic Symposium on Building Physics, Tampere, Finland (May,29 - June,2, 2011), pp.1237-1244

[29] EN 13779:2004, Ventilation for non-residential buildings - Performance requirements for ventilation and room conditioning systems

[30] Ham, M. J. Linssen, Bepaling benuttingsfactoren voor warmtebronnen en vrije koeling t.b.v. ontwerp NEN 2916, (1992) 


\section{Figure Captions}

Figure 1: Gain utilization factor $\eta_{\mathrm{H}, \mathrm{gn}}$ as a function of the heat-balance ratio $\gamma_{\mathrm{H}}$ for various time constants $\tau$ of the building using the dynamic parameters $\mathrm{a}_{0}$ and $\tau_{0}$ in accordance with EN ISO 13790 and the PASSYS project respectively

Figure 2: Impact of the inclusion of holiday periods on the gain utilization factor $\eta_{\mathrm{H}, \mathrm{gn}}$ for the months April (12 days off) and October (2 days off)

Figure 3: Schematic representation of prototype for primary education

Figure 4: Cumulative log normal probability function of the occupant density rate for elementary education. $\mu$ is the mean value and $\sigma$ is the standard deviation of the corresponding probability function.

Figure 5: Results of the monthly gain utilization factor $\eta_{\mathrm{H}, \mathrm{gn}}$ as function of heat-balance ratio $\gamma_{\mathrm{H}}$ for various thermal capacities of the building. Grey zones: between minimum and maximum values. The dashed lines represent the average result.

Figure 6: The averages of the results of the monthly gain utilization factor $\eta_{\mathrm{H}, \mathrm{gn}}$ as function of heat-balance ratio $\gamma_{\mathrm{H}}$ for various thermal capacities of the building. 
Figure 7: Daily heating and temperature pattern on a regular school day (Tuesday $6^{\text {th }}$ of February) in winter time for a light $\left(\mathrm{C}_{\mathrm{m}}=3.28 * 10^{8} \mathrm{~J} / \mathrm{K}\right)$ and heavy $\left(\mathrm{C}_{\mathrm{m}}=7.27 * 10^{8} \mathrm{~J} / \mathrm{K}\right)$ structure with a global insulation level of $\mathrm{U}_{\text {mean }}=0.17 \mathrm{~W} /\left(\mathrm{m}^{2} . \mathrm{K}\right), \mathrm{n}_{50}=0.6 \mathrm{~h}^{-1}$

Figure 8: Weekly heating and temperature pattern on a regular school week (Monday $5^{\text {th }}$ of February - Sunday $12^{\text {th }}$ of February) in winter time for a light $\left(\mathrm{C}_{\mathrm{m}}=3.28 * 10^{8} \mathrm{~J} / \mathrm{K}\right)$ and heavy $\left(\mathrm{C}_{\mathrm{m}}=7.27 * 10^{8} \mathrm{~J} / \mathrm{K}\right)$ structure with a global isolation level of $\mathrm{U}_{\text {mean }}=0.17 \mathrm{~W} /\left(\mathrm{m}^{2} . \mathrm{K}\right), \mathrm{n}_{50}=$ $0.6 \mathrm{~h}^{-1}$

Figure 9: the absolute difference between the dynamically $\left(\mathrm{Q}_{\mathrm{H}, \mathrm{nd}, \mathrm{dyn}}\right)$ and statically calculated annual energy need for heating using respectively the original $\left(\mathrm{Q}_{\mathrm{H}, \mathrm{nd}, \mathrm{stat}, \mathrm{org}}\right)$ and adapted $\left(\mathrm{Q}_{\mathrm{H}, \mathrm{nd}, \text { stat,adap }}\right)$ dynamic parameters $\mathrm{a}_{0}$ and $\tau_{0}$

Figure 10: Gain utilization factor $\eta_{\mathrm{H}, \mathrm{gn}}$ as a function of the heat-balance ratio $\gamma_{\mathrm{H}}$ for a heavy $\left(\tau_{\text {mean }}=150\right)$ and very light $\left(\tau_{\text {mean }}=40\right)$ school building using the original dynamic parameters $\mathrm{a}_{0}=1$ and $\tau_{0}=15$ (dotted lines) and the adapted dynamic parameters $\mathrm{a}_{0}=1.4$ and $\tau_{0}=185$ (full lines)

Figure 11: Impact of the intermittent heating on the temperature pattern $\left(20^{\circ} \mathrm{C} / 16^{\circ} \mathrm{C}\right)$ on a regular school day (Thursday $8^{\text {th }}$ of February) for a light $\left(\mathrm{C}_{\mathrm{m}}=3.28 * 10^{8} \mathrm{~J} / \mathrm{K}\right)$ and heavy $\left(\mathrm{C}_{\mathrm{m}}\right.$ $\left.=7.27 * 10^{8} \mathrm{~J} / \mathrm{K}\right)$ structure with a global insulation level of a passive $\left(\mathrm{U}_{\text {mean }}=0.17 \mathrm{~W} /\left(\mathrm{m}^{2} . \mathrm{K}\right)\right)$ and reference building $\left(\mathrm{U}_{\text {mean }}=0.43 \mathrm{~W} /\left(\mathrm{m}^{2} . \mathrm{K}\right)\right)$ 
Figure 1

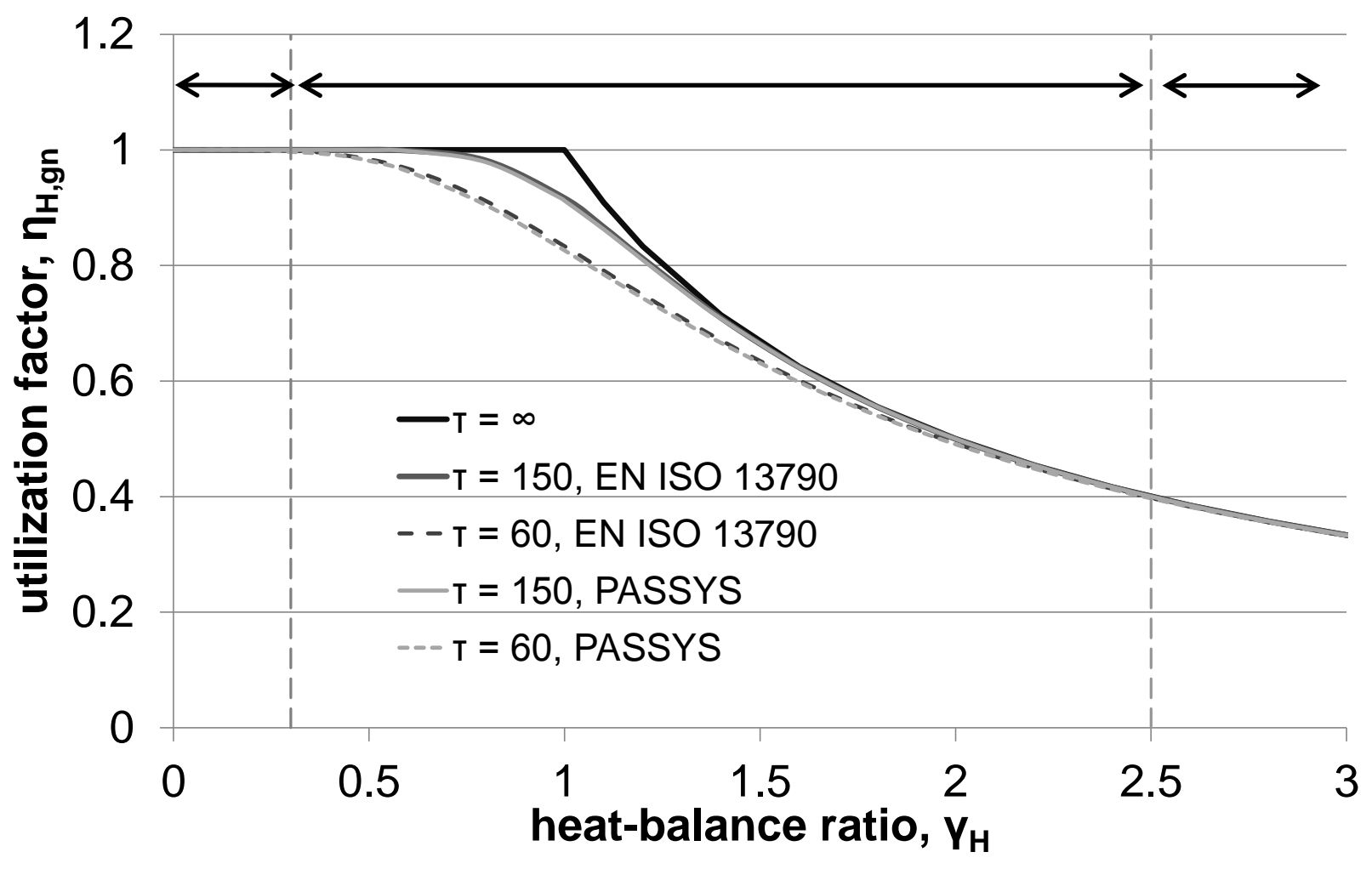


Figure 2

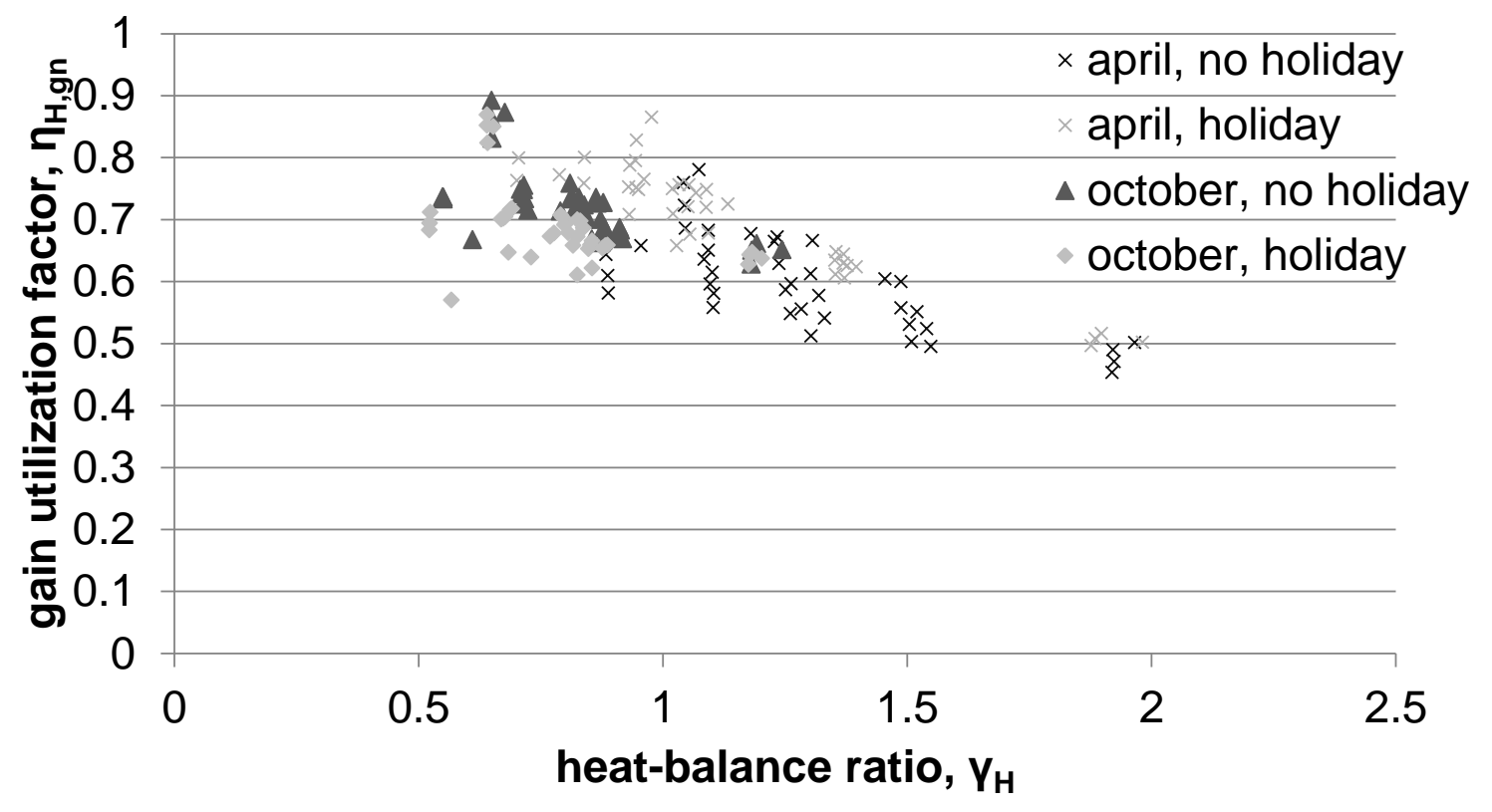


Figure 3

FRONT 8482

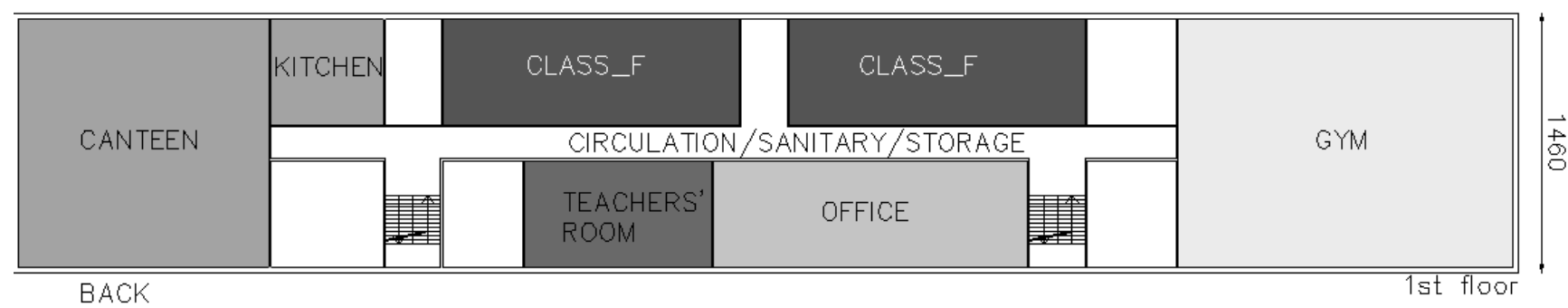

FRONT

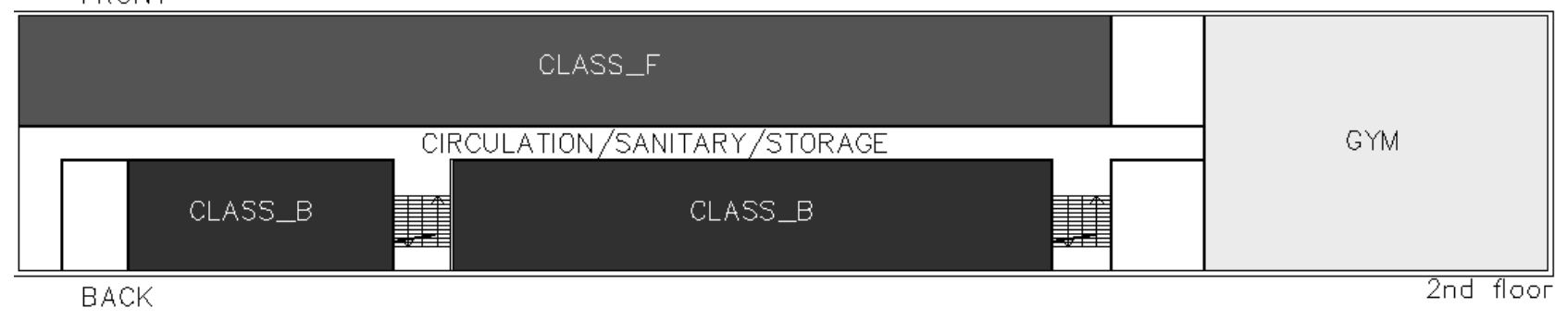


Figure 4

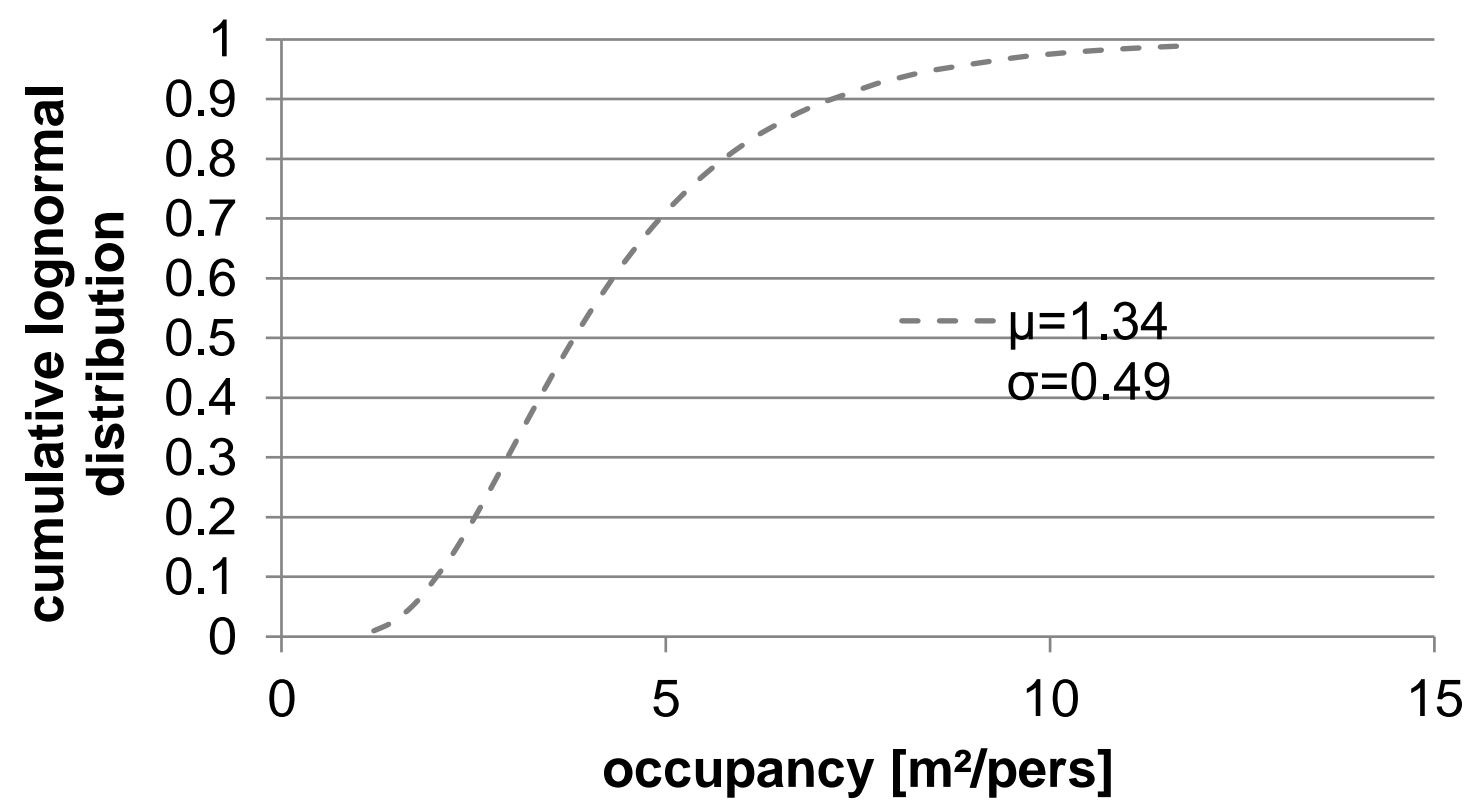




\section{Figure 5}
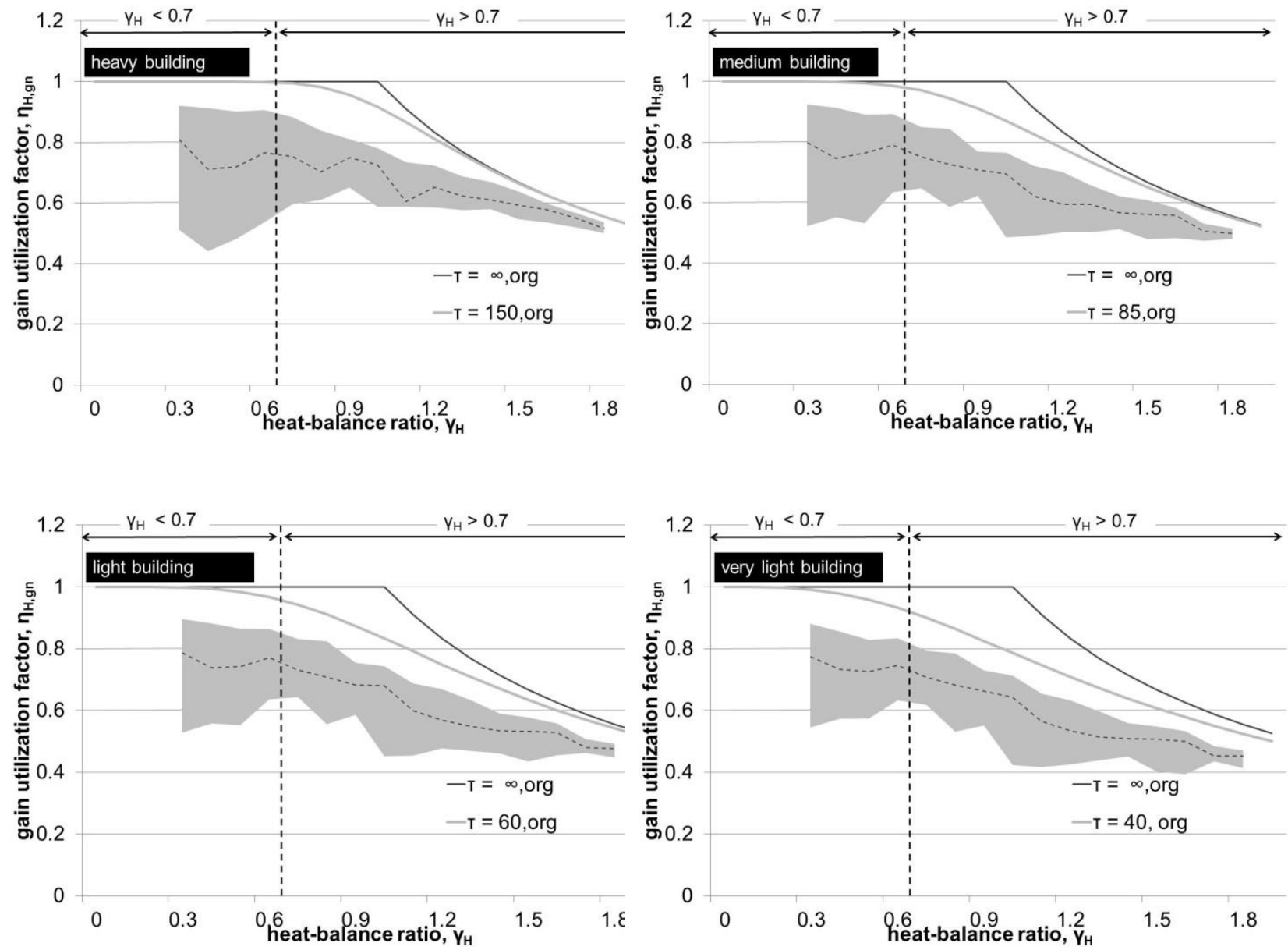
Figure 6

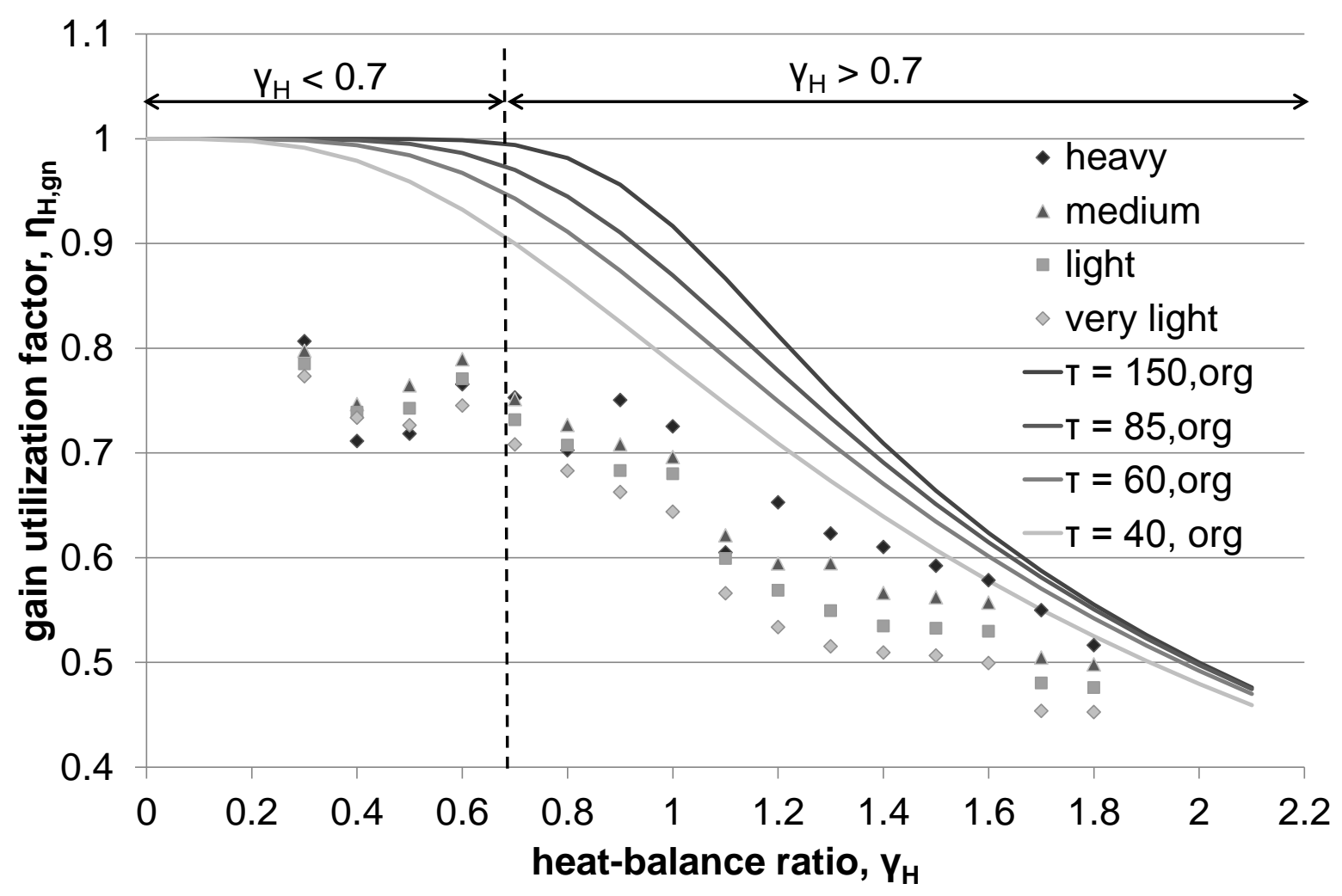


Figure 7

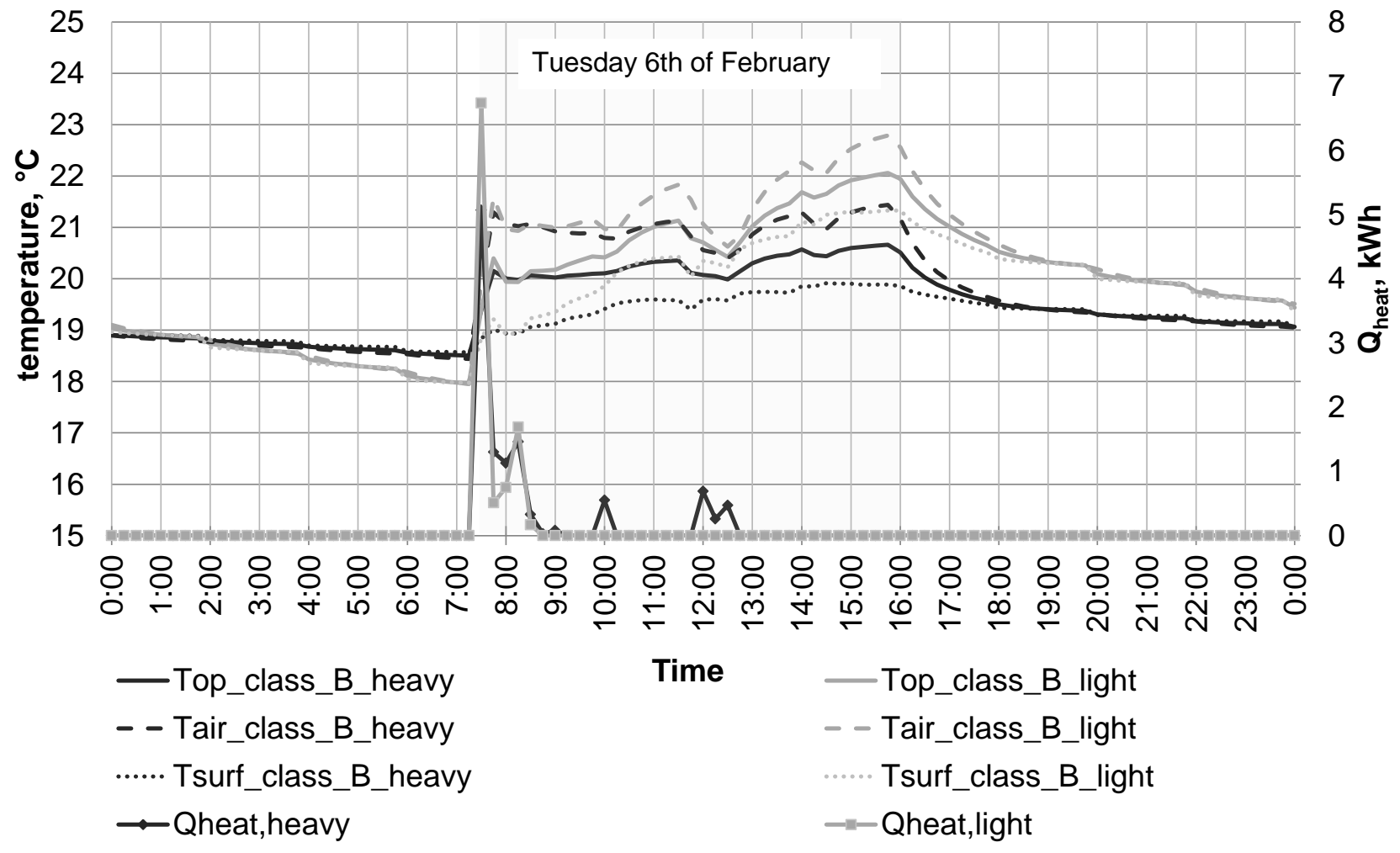


Figure 8

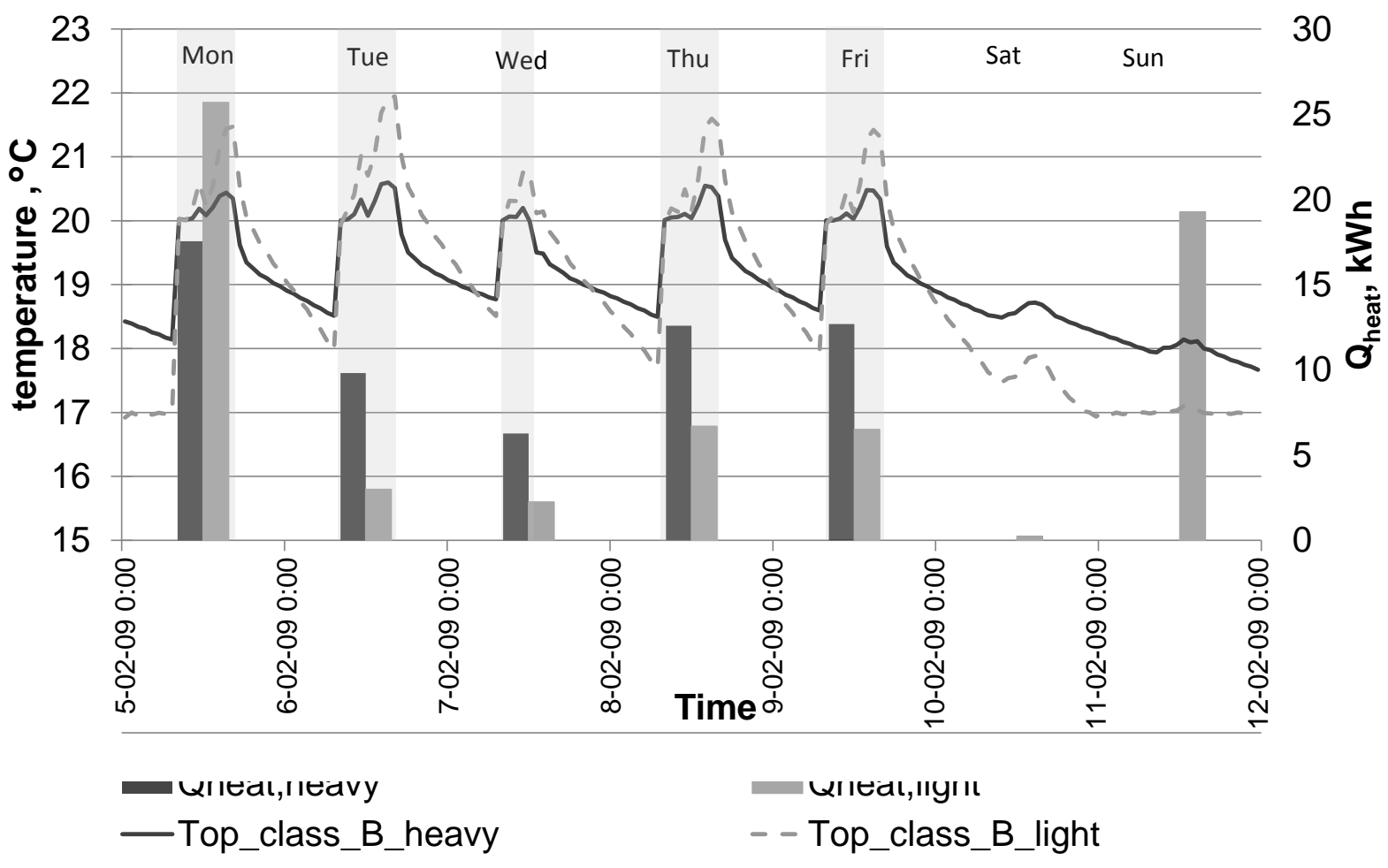


Figure 9

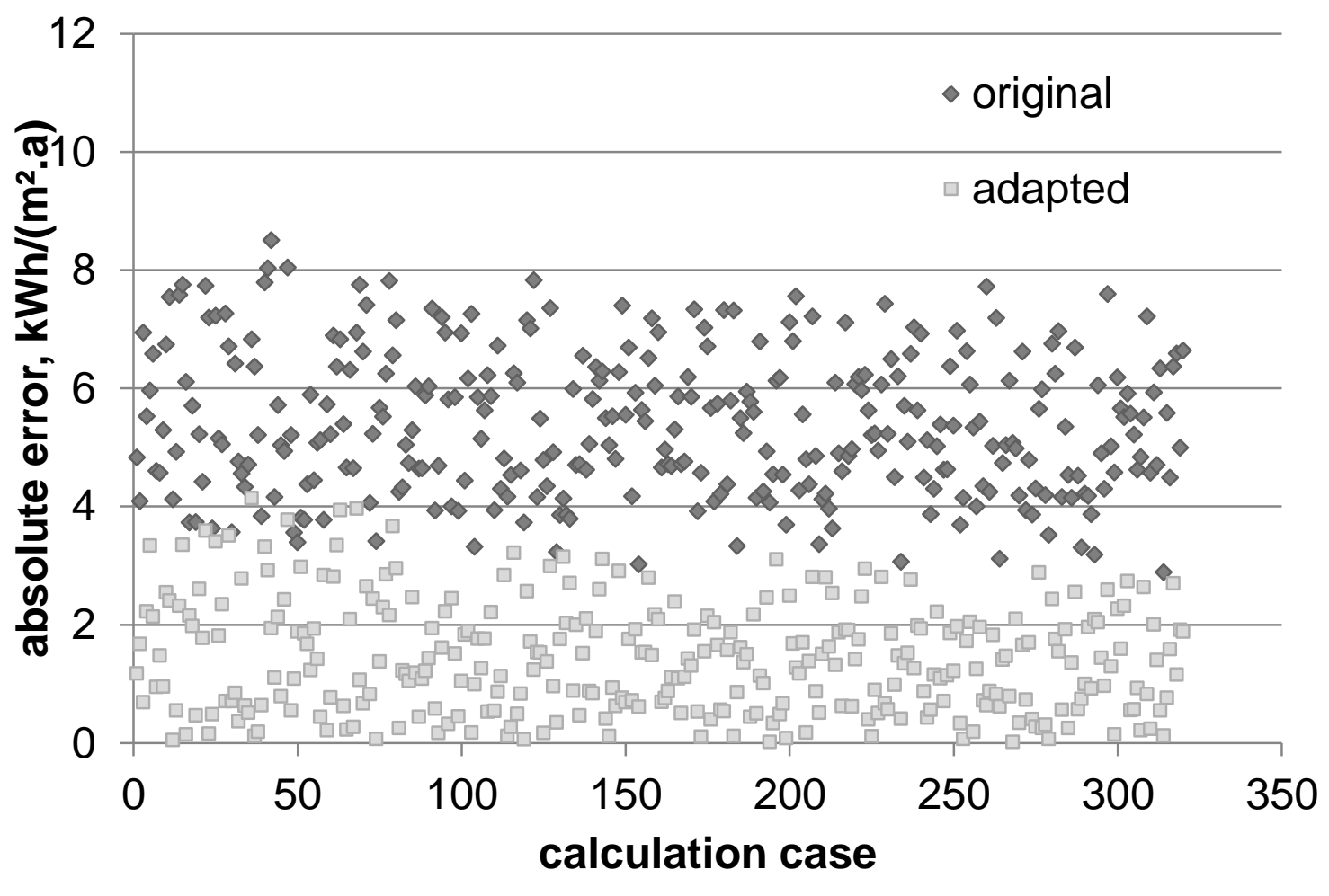


Figure 10

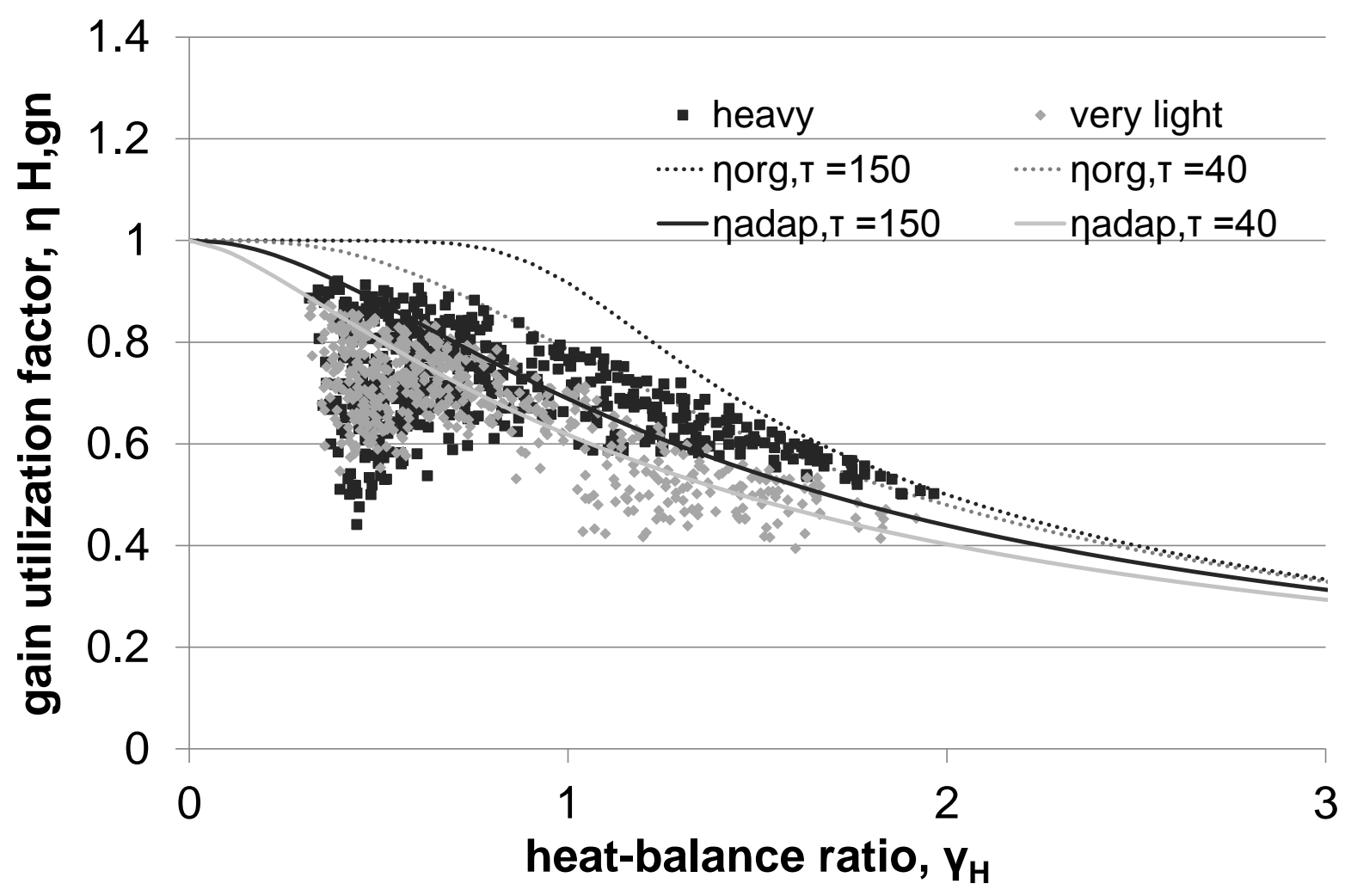


Figure 11

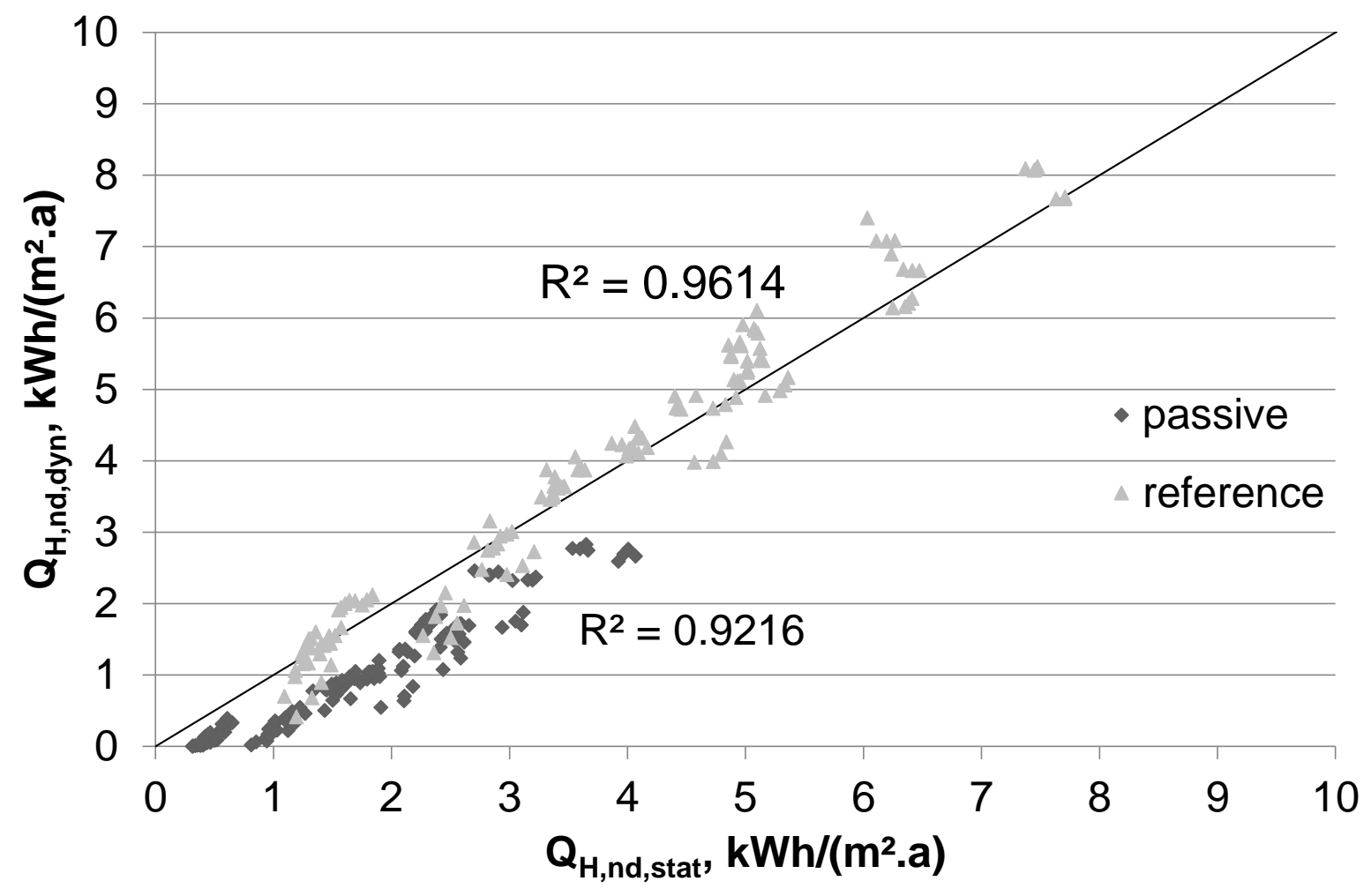




\section{Figure Captions}

Figure 1: Gain utilization factor $\eta_{\mathrm{H}, \mathrm{gn}}$ as a function of the heat-balance ratio $\gamma_{\mathrm{H}}$ for various time constants $\tau$ of the building using the dynamic parameters $\mathrm{a}_{0}$ and $\tau_{0}$ in accordance with EN ISO 13790 and the PASSYS project respectively

Figure 2: Impact of the inclusion of holiday periods on the gain utilization factor $\eta_{\mathrm{H}, \mathrm{gn}}$ for the months April (12 days off) and October (2 days off)

Figure 3: Schematic representation of prototype for primary education

Figure 4: Cumulative log normal probability function of the occupant density rate for elementary education. $\mu$ is the mean value and $\sigma$ is the standard deviation of the corresponding probability function.

Figure 5: Results of the monthly gain utilization factor $\eta_{\mathrm{H}, \mathrm{gn}}$ as function of heat-balance ratio $\gamma_{\mathrm{H}}$ for various thermal capacities of the building. Grey zones: between minimum and maximum values. The dashed lines represent the average result.

Figure 6: The averages of the results of the monthly gain utilization factor $\eta_{\mathrm{H}, \mathrm{gn}}$ as function of heat-balance ratio $\gamma_{\mathrm{H}}$ for various thermal capacities of the building.

Figure 7: Daily heating and temperature pattern on a regular school day (Tuesday $6^{\text {th }}$ of February) in winter time for a light $\left(\mathrm{C}_{\mathrm{m}}=3.28 * 10^{8} \mathrm{~J} / \mathrm{K}\right)$ and heavy $\left(\mathrm{C}_{\mathrm{m}}=7.27 * 10^{8} \mathrm{~J} / \mathrm{K}\right)$ structure with a global insulation level of $\mathrm{U}_{\text {mean }}=0.17 \mathrm{~W} /\left(\mathrm{m}^{2} \cdot \mathrm{K}\right), \mathrm{n}_{50}=0.6 \mathrm{~h}^{-1}$

Figure 8: Weekly heating and temperature pattern on a regular school week (Monday $5^{\text {th }}$ of February - Sunday $12^{\text {th }}$ of February) in winter time for a light $\left(\mathrm{C}_{\mathrm{m}}=3.28 * 10^{8} \mathrm{~J} / \mathrm{K}\right)$ and heavy $\left(\mathrm{C}_{\mathrm{m}}=7.27 * 10^{8} \mathrm{~J} / \mathrm{K}\right)$ structure with a global isolation level of $\mathrm{U}_{\text {mean }}=0.17 \mathrm{~W} /\left(\mathrm{m}^{2} . \mathrm{K}\right), \mathrm{n}_{50}=$ $0.6 \mathrm{~h}^{-1}$

Figure 9: the absolute difference between the dynamically $\left(\mathrm{Q}_{\mathrm{H}, \mathrm{nd}, \mathrm{dyn}}\right)$ and statically calculated annual energy need for heating using respectively the original $\left(\mathrm{Q}_{\mathrm{H}, \mathrm{nd} \text {,stat,org }}\right)$ and adapted ( $\left.\mathrm{Q}_{\mathrm{H}, \mathrm{nd}, \mathrm{stat}, \text { adap }}\right)$ dynamic parameters $\mathrm{a}_{0}$ and $\tau_{0}$

Figure 10: Gain utilization factor $\eta_{H, g n}$ as a function of the heat-balance ratio $\gamma_{H}$ for a heavy $\left(\tau_{\text {mean }}=150\right)$ and very light $\left(\tau_{\text {mean }}=40\right)$ school building using the original dynamic parameters $\mathrm{a}_{0}=1$ and $\tau_{0}=15$ (dotted lines) and the adapted dynamic parameters $\mathrm{a}_{0}=1.4$ and $\tau_{0}=185$ (full lines)

Figure 11: Impact of the intermittent heating on the temperature pattern $\left(20^{\circ} \mathrm{C} / 16^{\circ} \mathrm{C}\right)$ on a regular school day (Thursday $8^{\text {th }}$ of February) for a light $\left(\mathrm{C}_{\mathrm{m}}=3.28 * 10^{8} \mathrm{~J} / \mathrm{K}\right)$ and heavy $\left(\mathrm{C}_{\mathrm{m}}\right.$ $\left.=7.27 * 10^{8} \mathrm{~J} / \mathrm{K}\right)$ structure with a global insulation level of a passive $\left(\mathrm{U}_{\text {mean }}=0.17 \mathrm{~W} /\left(\mathrm{m}^{2} . \mathrm{K}\right)\right)$ and reference building $\left(\mathrm{U}_{\text {mean }}=0.43 \mathrm{~W} /\left(\mathrm{m}^{2} . \mathrm{K}\right)\right)$ 
Table 1: Overview of the Flemish school calendar

\begin{tabular}{lcccccccccccc}
\hline EN ISO 13790 & Jan & Feb & Mar & Apr & May & June & July & Aug & Sept & Oct & Nov & Dec \\
\hline weekday & 14 & 14 & 16 & 7 & 15 & 16 & 0 & 0 & 16 & 16 & 16 & 12 \\
\hline wednesday & 4 & 3 & 4 & 2 & 5 & 4 & 4 & 5 & 4 & 4 & 4 & 3 \\
\hline weekend & 8 & 8 & 9 & 9 & 8 & 9 & 9 & 8 & 10 & 8 & 8 & 10 \\
\hline holiday & 5 & 3 & 2 & 12 & 3 & 1 & 31 & 31 & 0 & 3 & 2 & 6 \\
\hline total & $\mathbf{3 1}$ & $\mathbf{2 8}$ & $\mathbf{3 1}$ & $\mathbf{3 0}$ & $\mathbf{3 1}$ & $\mathbf{3 0}$ & $\mathbf{3 1}$ & $\mathbf{3 1}$ & $\mathbf{3 0}$ & $\mathbf{3 1}$ & $\mathbf{3 0}$ & $\mathbf{3 1}$ \\
\hline
\end{tabular}

Table 2: Overview of the school calendar: determination of the monthly holiday fraction

\begin{tabular}{lcccccccccccc}
\hline EN ISO 13790 & Jan & Feb & Mar & Apr & May & June & July & Aug & Sept & Oct & Nov & Dec \\
\hline holiday & 5 & 3 & 2 & 12 & 3 & 1 & 31 & 31 & 0 & 3 & 2 & 6 \\
\hline total & 31 & 28 & 31 & 30 & 31 & 30 & 31 & 31 & 30 & 31 & 30 & 31 \\
\hline$f_{\text {H,occ,hol }}$ & $\mathbf{0 . 1 6}$ & $\mathbf{0 . 1 1}$ & $\mathbf{0 . 0 7}$ & $\mathbf{0 . 4 0}$ & $\mathbf{0 . 1 0}$ & $\mathbf{0 . 0 3}$ & $\mathbf{1}$ & $\mathbf{1}$ & $\mathbf{0}$ & $\mathbf{0 . 1 0}$ & $\mathbf{0 . 0 7}$ & $\mathbf{0 . 1 9}$ \\
\hline
\end{tabular}

Table 3: General building data

\begin{tabular}{cl}
\hline Type model primary education & \\
\hline General building data & \\
\hline number of students & 250 students \\
\hline gross floor area & $2477 \mathrm{~m}^{2}$ \\
\hline useable floor area & $2057 \mathrm{~m}^{2}$ \\
\hline building volume & $6570 \mathrm{~m}^{3}$ \\
\hline number of floors & 2 \\
\hline Envelope surface area & \\
\hline roof & $1212 \mathrm{~m}^{2}$ \\
\hline floor & $1212 \mathrm{~m}^{2}$ \\
\hline external wall & $1271 \mathrm{~m}^{2}$ \\
\hline window & variable $(\mathrm{see} \S 3.2 .3)$ \\
\hline sum envelope surface area & $3694 \mathrm{~m}^{2}$ \\
\hline Level of compactness & $1.78 \mathrm{~m}$ \\
\hline
\end{tabular}


Table 4: Overview of deterministic internal heat gains due to people, lighting and applications

\begin{tabular}{|c|c|c|c|}
\hline & 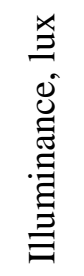 & 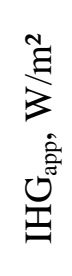 & 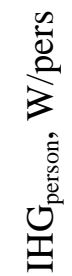 \\
\hline class room & 300 & 1 & 60 \\
\hline computer lab & 300 & 30 & 60 \\
\hline office & 500 & 10 & 80 \\
\hline teachers' room & 500 & 2.5 & 80 \\
\hline gym & 300 & - & 160 \\
\hline canteen & 300 & 1 & 60 \\
\hline kitchen & 500 & 80 & 100 \\
\hline sanitary & 200 & - & - \\
\hline storage room & - & - & - \\
\hline circulation area & 100 & - & - \\
\hline
\end{tabular}

Table 5: Variation of thermal mass for primary school building

\begin{tabular}{lll}
\hline \multicolumn{2}{c}{ HEAT CAPACITY $\mathbf{C}_{\mathrm{m}}$} & \multicolumn{1}{c}{ CONSTRUCTION } \\
\hline Heavy & $7.27 * 10^{8} \mathrm{~J} / \mathrm{K}$ & all heavy \\
\hline Medium & $4.64 * 10^{8} \mathrm{~J} / \mathrm{K}$ & $\begin{array}{l}\text { heavy (intermediate) floor \& external wall, } \\
\text { light roof and internal walls }\end{array}$ \\
\hline Light & $3.28 * 10^{8} \mathrm{~J} / \mathrm{K}$ & $\begin{array}{l}\text { light roof, external \& internal walls, heavy } \\
\text { (intermediate) floor }\end{array}$ \\
\hline Very light & $2.19 * 10^{8} \mathrm{~J} / \mathrm{K}$ & $\begin{array}{l}\text { light roof, intermediate floor, external \& } \\
\text { internal walls, heavy ground level floor }\end{array}$ \\
\hline
\end{tabular}


Table 6: Composition of structural elements (from front/inside to back/outside)

\begin{tabular}{|c|c|c|c|c|c|}
\hline & material & $\begin{array}{l}\lambda, \\
\mathrm{W} /(\mathrm{m} . \mathrm{K})\end{array}$ & $\begin{array}{l}\mathrm{c}, \\
\mathrm{J} /(\mathrm{kg} . \mathrm{K})\end{array}$ & $\begin{array}{l}\rho, \\
\mathrm{kg} / \mathrm{m}^{3}\end{array}$ & $\begin{array}{l}\text { thickness, } \\
\mathrm{m}\end{array}$ \\
\hline \multirow[t]{4}{*}{ roof_light } & gypsum board & 0.24 & 1000 & 750 & 0.012 \\
\hline & mineral wool (MW) & 0.040 & 1030 & 50 & Table 7 \\
\hline & OSB & 0.13 & 1700 & 650 & 0.018 \\
\hline & EPDM & 0.25 & 1000 & 1150 & 0.002 \\
\hline \multirow[t]{5}{*}{ roof_heavy } & plaster finish & 0.52 & 1000 & 1300 & 0.010 \\
\hline & heavy concrete & 1.70 & 1000 & 2400 & 0.150 \\
\hline & light concrete & 0.32 & 1000 & 1050 & 0.100 \\
\hline & PUR & 0.030 & 1400 & 30 & Table 7 \\
\hline & Bitumen & 0.23 & 1000 & 1100 & 0.002 \\
\hline \multirow[t]{4}{*}{ ext_wall_light } & gypsum board & 0.24 & 1000 & 750 & 0.012 \\
\hline & OSB & 0.13 & 1700 & 650 & 0.015 \\
\hline & MW & 0.040 & 1030 & 50 & Table 7 \\
\hline & wood fibreboard & 0.50 & 2100 & 24 & 0.018 \\
\hline \multirow{3}{*}{ ext_wall_heavy } & plaster finish & 0.52 & 1000 & 1300 & 0.010 \\
\hline & brickwork & 0.54 & 1000 & 1550 & 0.140 \\
\hline & PUR & 0.030 & 1400 & 30 & Table 7 \\
\hline \multirow[t]{5}{*}{ floor } & tiles & 1.2 & 840 & 2300 & 0.010 \\
\hline & light concrete & 0.32 & 1000 & 1050 & 0.100 \\
\hline & PUR & 0.030 & 1400 & 30 & Table 7 \\
\hline & heavy concrete & 1.70 & 1000 & 2400 & 0.150 \\
\hline & bitumen & 0.23 & 1000 & 1100 & 0.002 \\
\hline \multirow[t]{3}{*}{ int_wall_light } & gypsum board (2 x) & 0.24 & 1000 & 750 & $2 \times 0.012$ \\
\hline & MW & 0.04 & 1030 & 50 & 0.14 \\
\hline & gypsum board (2x) & 0.24 & 1000 & 750 & $2 \times 0.012$ \\
\hline \multirow[t]{3}{*}{ int_wall_heavy } & plaster finish & 0.52 & 1000 & 1300 & 0.010 \\
\hline & brickwork & 0.54 & 1000 & 1250 & 0.140 \\
\hline & plaster finish & 0.52 & 1000 & 1300 & 0.010 \\
\hline \multirow[t]{5}{*}{ interm_floor_light } & linoleum & 0.623 & 1400 & 1200 & 0.003 \\
\hline & OSB & 0.13 & 1700 & 650 & 0.018 \\
\hline & wood fibreboard & 0.055 & 2100 & 24 & 0.03 \\
\hline & MW & 0.062 & 1030 & 50 & 0.2 \\
\hline & gypsum board & 0.24 & 1000 & 750 & 0.012 \\
\hline \multirow[t]{5}{*}{ interm_floor_heavy } & tiles & 1.2 & 840 & 2300 & 0.02 \\
\hline & chape & 1.35 & 840 & 1000 & 0.10 \\
\hline & PUR & 0.03 & 1400 & 30 & 0.03 \\
\hline & heavy concrete & 1.73 & 1000 & 2400 & 0.04 \\
\hline & $\begin{array}{l}\text { hollow core concrete } \\
\text { slab }\end{array}$ & 0.92 & 840 & 1500 & 0.12 \\
\hline
\end{tabular}


Table 7: Overview of material properties

\begin{tabular}{lll}
\hline & material & thickness, $\mathbf{~}$ \\
\hline roof_light & mineral wool & $0.21->0.56$ \\
\hline roof_heavy & PUR & $0.09->0.25$ \\
\hline wall_light & mineral wool & $0.13->0.35$ \\
\hline wall_heavy & PUR & $0.07->0.18$ \\
\hline floor & PUR & $0.07->0.18$ \\
\hline & frame & glazing \\
\hline window_1 & thermally insulated & $\mathrm{U}=1.12 \mathrm{~W} /\left(\mathrm{m}^{2} \cdot \mathrm{K}\right)$ \\
& & $\mathrm{g}=0.57$ \\
\hline window_2 & thermally insulated & $\mathrm{U}=0.78 \mathrm{~W} /\left(\mathrm{m}^{2} \cdot \mathrm{K}\right)$ \\
& & $\mathrm{g}=0.55$ \\
\hline
\end{tabular}

Table 8: Dynamically and statically calculated annual heating demand $Q_{H, n d}, \mathrm{kWh} /\left(\mathrm{m}^{2} . a\right)$.

\begin{tabular}{llll}
\hline & $\mathrm{Q}_{\mathrm{H}, \text { nd,dyn }}$ & $\begin{array}{l}\mathrm{Q}_{\mathrm{H}, \text { nd,stat,org }} \\
\mathrm{a}_{0}=1, \tau_{0}=15\end{array}$ & $\begin{array}{l}\mathrm{Q}_{\mathrm{H}, \text { nd,stat,adap }} \\
\mathrm{a}_{0}=1.4, \tau_{0}=185\end{array}$ \\
\hline $\max$ & 34.46 & 29.35 & 34.95 \\
\hline $\operatorname{mean}$ & 21.14 & 15.75 & 20.60 \\
\hline $\min$ & 10.54 & 5.02 & 8.26 \\
\hline
\end{tabular}

Table 9: Evaluation of the implementation of adapted dynamic parameters $a_{0}$ and $\tau_{0}$ : average absolute and relative differences

\begin{tabular}{lcc}
\hline & $\left|\mathrm{Q}_{\mathrm{H}, \mathrm{ht}}-\eta_{\mathrm{H}, \mathrm{gn}} \mathrm{Q}_{\mathrm{H}, \mathrm{gn}}\right|$ & $\left|\mathrm{Q}_{\mathrm{H}, \mathrm{ht}}-\eta_{\mathrm{H}, \mathrm{gn}} \mathrm{Q}_{\mathrm{H}, \mathrm{gn}}\right| / \mathrm{Q}_{\mathrm{H}, \mathrm{nd}, \mathrm{dyn}, \text { annual }}$ \\
\hline$\eta_{\mathrm{gn}, \mathrm{org}}-$ EN ISO 13790 & $5.39 \mathrm{kWh} /\left(\mathrm{m}^{2} . \mathrm{a}\right)$ & $3.75 \%$ \\
$\left(\mathrm{a}_{0}=1, \tau_{0}=15\right)$ & & \\
\hline$\eta_{\text {gn,adap }}-$ adapted & & \\
school buildings & $1.41 \mathrm{kWh} /\left(\mathrm{m}^{2} \cdot \mathrm{a}\right)$ & \\
$\left(\mathrm{a}_{0}=1.4, \tau_{0}=185\right)$ & & \\
\hline
\end{tabular}

Table 10: Dynamically and statically calculated monthly average operative temperature in February for a light $\left(C_{m}=3.28 * 108 \mathrm{~J} / \mathrm{K}\right)$ and heavy $\left(C_{m}=7.27 * 108 \mathrm{~J} / \mathrm{K}\right)$ structure with a global insulation level of a passive $\left(U_{\text {mean }}=0.17 \mathrm{~W} /\left(\mathrm{m}^{2} . K\right)\right)$ and reference building $\left(U_{\text {mean }}=\right.$ $\left.0.43 \mathrm{~W} /\left(\mathrm{m}^{2} . K\right)\right)$

\begin{tabular}{|c|c|c|c|c|}
\hline & \multicolumn{2}{|c|}{ Reference building } & \multicolumn{2}{|c|}{ Passive building } \\
\hline & Heavy & Light & Heavy & Light \\
\hline$\Theta_{\mathrm{i}, \mathrm{mean}, \mathrm{dyn}}$ & $18.1^{\circ} \mathrm{C}$ & $17.8^{\circ} \mathrm{C}$ & $19.5^{\circ} \mathrm{C}$ & $19.3^{\circ} \mathrm{C}$ \\
\hline$\Theta_{i, \text { mean,stat }}$ & $16.9^{\circ} \mathrm{C}$ & $16.9^{\circ} \mathrm{C}$ & $16.9^{\circ} \mathrm{C}$ & $16.9^{\circ} \mathrm{C}$ \\
\hline
\end{tabular}

